\title{
Morfologia externa comparada das três espécies do complexo Telchin licus (Drury) (Lepidoptera, Castniidae) com uma sinonímia
}

\author{
Simeão S. Moraes ${ }^{1,2} \&$ Marcelo Duarte ${ }^{2}$
}

${ }^{1}$ Curso de Pós-Graduação em Ciências Biológicas (Zoologia), Instituto de Biociências, Departamento de Zoologia, Universidade de São Paulo.

Rua do Matão, travessa 14, número 321.05508-900 São Paulo-SP, Brasil. simeao_moraes@yahoo.com.br

${ }^{2}$ Museu de Zoologia da Universidade de São Paulo, Avenida Nazaré 481, 04263-000 São Paulo-SP, Brasil.

\begin{abstract}
Comparative external morphology of the three species of the Telchin licus (Drury) complex (Lepidoptera, Castniidae) with a synonymy. A detailed morphological study of head, thorax, and abdomen is provided for three closely related species of Neotropical sun-moths. The taxonomic position of these species is controversial. Prior to the present study two of these species belonged to the genus Telchin Hübner, 1825, and one to the monotypic genus Castniomera Houlbert, 1918 (type species: Castnia atymnius Dalman, 1824). The hypothesis of some authors of placing the three species in a single genus is here supported on morphological evidences from head, thorax, and abdomen. Castniomera Houlbert is treated as synonym of Telchin Hübner comprising the following species: Telchin licus (Drury, 1773), Telchin syphax (Fabricius, 1775), and Telchin atymnius (Dalman) new combination. The three species of the T. licus complex are illustrated with line drawings and color photographs.
\end{abstract}

KEYWORDS. Castniid moth; morphological variation; Neotropical; taxonomy.

\begin{abstract}
RESUMO. Morfologia externa comparada das três espécies do complexo Telchin licus (Drury) (Lepidoptera, Castniidae) com uma sinonímia. É apresentado um estudo morfológico detalhado da cabeça, do tórax e do abdome de três espécies próximas de castníideos neotropicais. O posicionamento taxonômico dessas espécies é ainda bastante controverso. Antes do desenvolvimento do presente estudo, duas dessas espécies pertenciam ao gênero Telchin Hübner, 1825 e uma ao gênero monotípico Castniomera Houlbert, 1918 (espécie-tipo: Castnia atymnius Dalman, 1824). A hipótese de alguns autores de incluir as três espécies do complexo T. licus em um único gênero é aqui sustentada com base em evidências morfológicas de cabeça, tórax e abdome. Castniomera Houlbert torna-se sinônimo de Telchin Hübner compreendendo as seguintes espécies: Telchin licus (Drury, 1773), Telchin syphax (Fabricius, 1775) e Telchin atymnius (Dalman) combinação nova. As três espécies do complexo T. licus são ilustradas com desenhos e fotografias coloridas.
\end{abstract}

PALAVRAS-CHAVE. Castníideo; neotropical; taxonomia; variação morfológica.

Com pouco mais de 150 espécies válidas, Castniidae inclui as subfamílias Castniinae e Tascininae (sensu Edwards et al. 1998). Castniinae é a única que possui representantes na região neotropical que, atualmente, estão arrolados em Castniini e Gazerini. Castniinae inclui ainda Synemonini, com 43 espécies pertencentes ao gênero australiano Synemon Doubleday, 1846.

Castniini e Gazerini (sensu Miller 1995) distribuem-se do México até o Chile e Argentina. Ao todo são reconhecidas 84 espécies (Lamas 1995; Pierre \& Pierre-Baltus 2003; Porion 2004; Espinoza \& González 2005). Gazerini difere de Castniini pela presença de androcônias abdominais e pelo fato de muitas espécies formarem complexos miméticos com outros grupos de Lepidoptera, como por exemplo, Ithomiinae e Nymphalinae (Nymphalidae) (Lamas 1973; Miller 1986). No entanto, os limites das duas tribos são ainda bastante ambíguos.

As espécies neotropicais de Castniinae têm hábitos diurnos, com atividades nos períodos mais quentes do dia, geralmente entre 10:00 e 14:00 horas (Strand 1913; Edwards et al. 1998). A principal característica desses lepidópteros são as antenas clavadas, geralmente estendidas formando um apículo (Scoble 1992). A maioria das espécies possui coloração críptica ou padrão disruptivo nas asas anteriores, enquanto as posteriores são caracteristicamente coloridas. Em geral, apresentam escamas iridescentes em diferentes regiões do corpo. As larvas são brocadoras de troncos e raízes e forrageiam quase que exclusivamente sobre monocotiledôneas. Algumas espécies são economicamente importantes por serem pragas em cultivos de cana-de-açúcar, bananas, bromélias, palmeiras e orquídeas. $\mathrm{O}$ fato de o Brasil abrigar 65 espécies, o que corresponde a aproximadamente $61 \%$ da fauna neotropical de Castniidae (Miller 2000), torna o país uma importante região para estudos com a família.

Entre os estudos realizados com Lepidoptera, aqueles que tratam do entendimento da morfologia comparada estão entre os mais escassos (Duarte et al. 2001). Estudos dessa natureza são importantes para melhor entendimento da variação morfológica inter e intraespecífica e de aspectos ecológicos e comportamentais, auxiliando na resolução de problemas taxonômicos e no entendimento da evolução do grupo.

Telchin licus (Drury, 1773) é um dos castníideos mais comuns em coleções científicas (González 2003; S. Moraes obs. pess.). É importante praga agrícola em cultivos de canade-açúcar (González 2003). Contudo, são escassos os estudos acerca de sua morfologia e relações de parentesco com as demais espécies que formam o complexo T. licus: Telchin syphax (Fabricius, 1775) e Castniomera atymnius (Dalman, 
1824), o qual tem sido tradicionalmente mantido com base apenas no padrão de coloração alar (Miller 1986, 1995; Gonzaléz 2003).

Visando o melhor esclarecimento das relações de T. licus com grupos afins dentro de Castniini, desenvolveu-se um estudo morfológico comparado das estruturas da cabeça, do tórax e do abdome com as outras duas espécies supracitadas, que são pouco estudadas e raras em coleções. Apesar da possibilidade dessas três espécies formarem um grupo monofilético, até o momento nenhum estudo morfológico detalhado foi desenvolvido, de forma comparativa, para avaliar a variação morfológica existente entre os táxons, o que certamente, fornecerá subsídios para hipóteses filogenéticas suportadas em caracteres morfológicos mais informativos.

Miller (1986) tratou T. licus e T. syphax dentro de Leucocastnia Houlbert, 1918, subgênero de Castniomera Houlbert, 1918, com base no padrão de coloração das asas posteriores; como C. atymnius é espécie-tipo do gênero, manteve-a em um subgênero próprio. Em 1995, Miller, na checklist dos castníideos neotropicais, estabeleceu a combinação Erythrocastnia syphax e elevou Leucocastnia à categoria de gênero, com Leucocastnia licus e L. albomaculata (Houlbert, 1917). Lamas (1995) reformulou a checklist de Miller (1995), mantendo as três espécies em gêneros distintos, propondo a combinação Telchin licus com nota sobre a possibilidade dessa espécie e $C$. atymnius serem coespecíficas. Mais recentemente, González \& Cock (2004) realocaram E. syphax em Telchin, considerando o primeiro gênero como sinônimo subjetivo do segundo. Telchin Hübner, 1825 é o nome genérico mais antigo designado para Papilio licus Drury, 1773, o qual foi esquecido pela J. Y. Miller ao publicar a checklist em 1995.

Apesar de as espécies do complexo T. licus estarem atualmente alocadas em dois gêneros, a única característica relatada em estudos anteriores que as distingue são diferenças no padrão de coloração das asas posteriores. Telchin licus (Fig.1) e T. syphax (Fig. 2) são consideradas espécies congêneras (Miller 1986; González \& Cock 2004) pelo fato de possuírem máculas avermelhadas nas asas posteriores que não são compartilhadas com C. atymnius (Fig. 3). Além disso, o padrão de distribuição contínuo e com pontos de simpatria ao longo da região neotropical, a grande semelhança morfológica e os registros de forrageamento em Saccharum officinarum L. (Poaceae) e Musaceae para T. licus e $C$. atymnius, podem ser evidências de que tais espécies possam, de fato, compor um único gênero, de acordo com as hipóteses de Miller (1986).

\section{MATERIALE MÉTODOS}

Material biológico. O material utilizado nesse estudo faz parte da coleção de Lepidoptera do Museu de Zoologia da Universidade de São Paulo, Brasil. No total foram estudados 22 indivíduos machos e fêmeas (Tab. I).

No estudo da cabeça e do tórax foram dissecados indivíduos inteiros de T. licus e T. syphax sem dados de
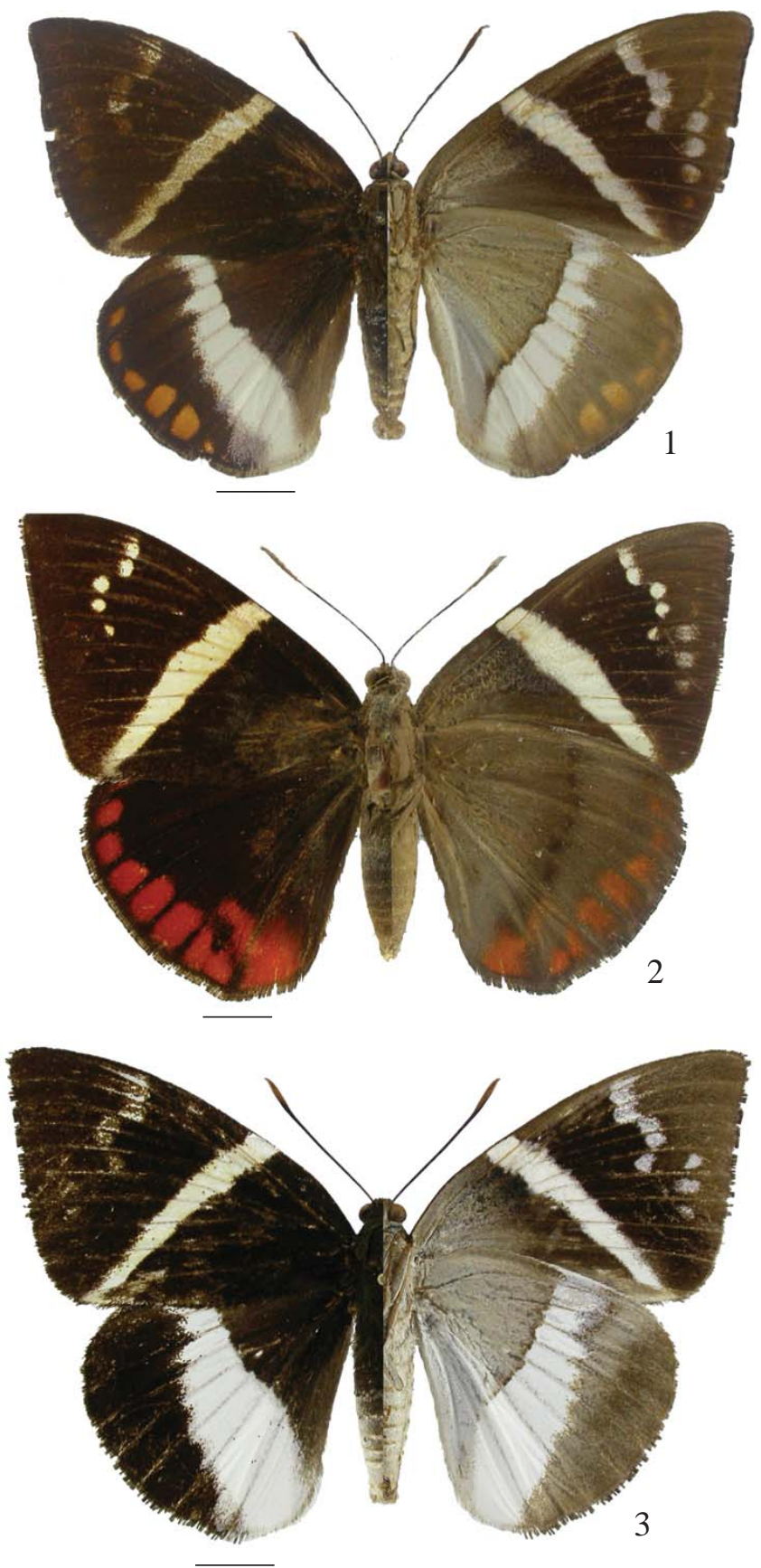

Figs. 1-3. Complexo T. licus (Drury), machos, vistas dorsal e ventral. 1. T. licus (Drury), Itacoatiara, AM. 2. T. syphax (Fabricius), Óbidos, PA. 3. T. atymnius (Dalman) comb. nov., Camacã, BA. Escala $=1 \mathrm{~cm}$.

procedência e período de coleta. Para C. atymnius foi utilizado apenas um indivíduo com procedência (Tab. I). A decisão de se utilizar preferencialmente indivíduos sem procedência é justificada pelo fato de os táxons aqui estudados serem, com exceção de T. licus, raros em quase todos os museus do mundo. Além disso, estudos de morfologia comparada em Lepidoptera exigem protocolos de dissecção que inviabilizam o retorno dos exemplares alfinetados à coleção (ver discussão em Duarte et al. 2001). Os exemplares dissecados foram acondicionados 

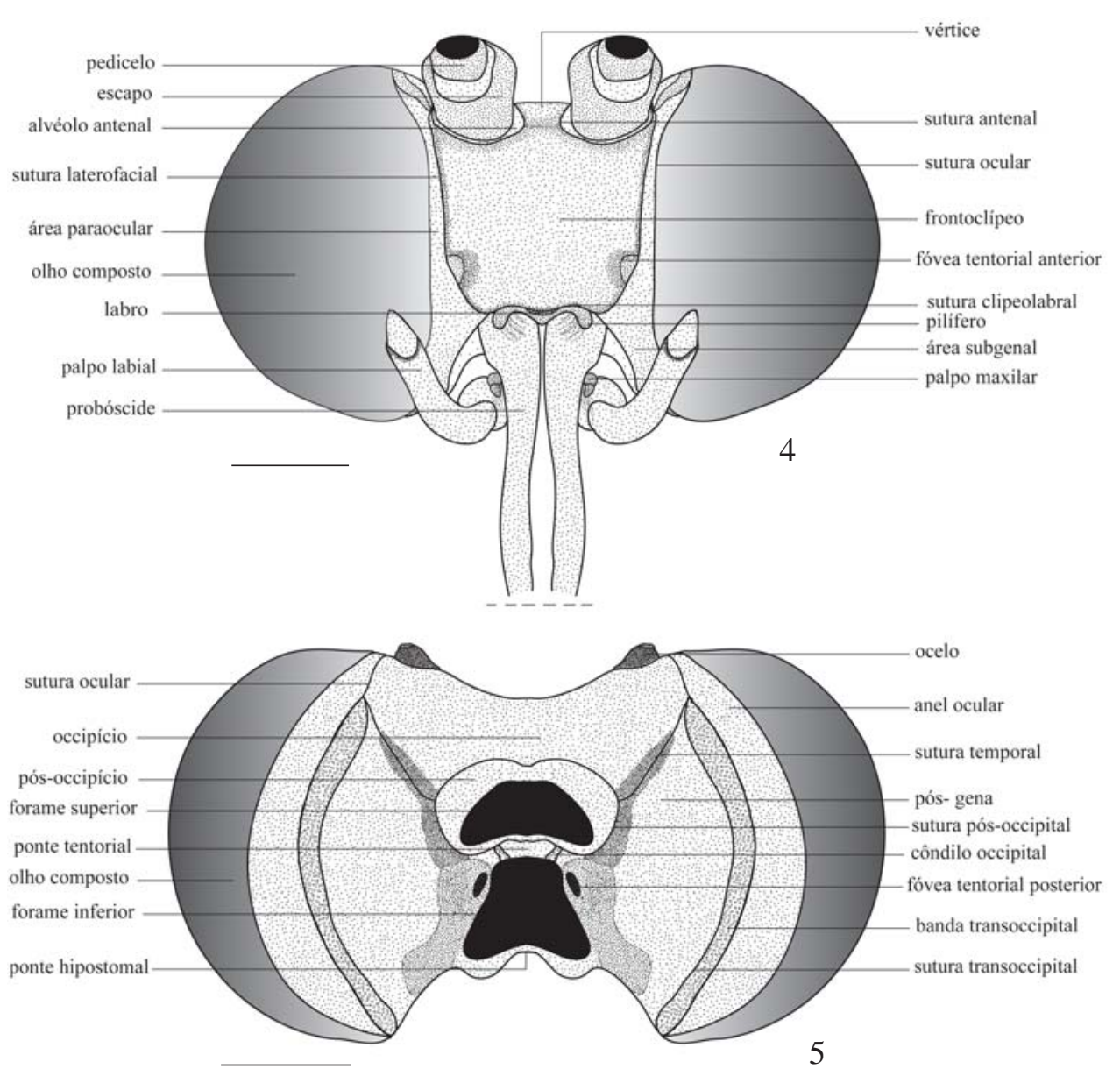

Figs. 4-5. Cabeça de T. licus (Drury). 4. Vista frontal. 5. Vista posterior. Escala $=1 \mathrm{~mm}$.

em glicerina dentro de pequenos frascos de vidro. Outros exemplares com procedência tiveram apenas as genitálias dissecadas que, após estudo, foram guardadas da mesma forma que os exemplares sem procedência, mantendo-as devidamente rotuladas e ao lado dos respectivos exemplares dissecados.

Metodologia. Exemplares machos de T. licus, T. syphax e C. atymnius tiveram as asas extraídas para estudo da venação. As asas foram mergulhadas em álcool $70 \%$ para remoção de gordura, diafanizadas em água sanitária, lavadas em água destilada e montadas sobre folhas de papel acetato. Após secagem, realizou-se o estudo da venação com a digitalização das lâminas de acetato e a confecção de desenhos no programa Adobe Illustrator 12.0. As asas foram medidas com auxílio de um paquímetro digital, sendo os valores dessas mensurações expressos como média e desvio-padrão (X+SD) (Tab. II).

O restante do corpo foi inicialmente lavado com álcool para remoção da gordura e mergulhado por inteiro em solução de hidróxido de potássio a $10 \%$, durante 24 horas, objetivando o amolecimento de tecidos e a clarificação do exoesqueleto. Após esse período, os espécimes foram lavados em água destilada para neutralizar o efeito do hidróxido de potássio (Ehrlich \& Ehrlich 1961). As escamas foram removidas com auxílio de pincéis e a dissecção realizada com estiletes, pinças e tesoura íris. Cabeça, tórax e abdome foram individualizados visando o estudo comparativo entre as espécies. As ilustrações dos tagmas e de seus apêndices foram feitas com auxílio de câmara clara acoplada a um estereomicroscópio, posteriormente digitalizadas e tratadas no programa Adobe Illustrator 12.0, para melhor acabamento dos desenhos a traço.

Para as fêmeas, realizou-se apenas o estudo do tagma abdominal e da venação alar, com procedimentos de dissecção e ilustração idênticos aos realizados com os machos.

Seguiu-se o trabalho de Miller (1971) para interpretação e descrição das estruturas da cabeça. Embora o foco desse trabalho tenha sido a superfamília Hesperioidea, ele é o único a abordar, com ilustrações, uma espécie de Castniidae: Castnia invaria Walker, 1854, na época citada como Castnia icarus (Cramer, [1775]). Para as demais regiões do corpo, seguiu-se algumas interpretações de Duarte et al. (2001) e Duarte (2007), baseadas em obras referenciadas de morfologia que também são citadas ao longo do presente trabalho. Procurou-se seguir a terminologia dessas obras, embora elas não tenham tratado especificamente de Castniidae. Nos casos onde ainda há reconhecida dificuldade em estabelecer homologias e a terminologia não parece ser adequada, recorre-se às 

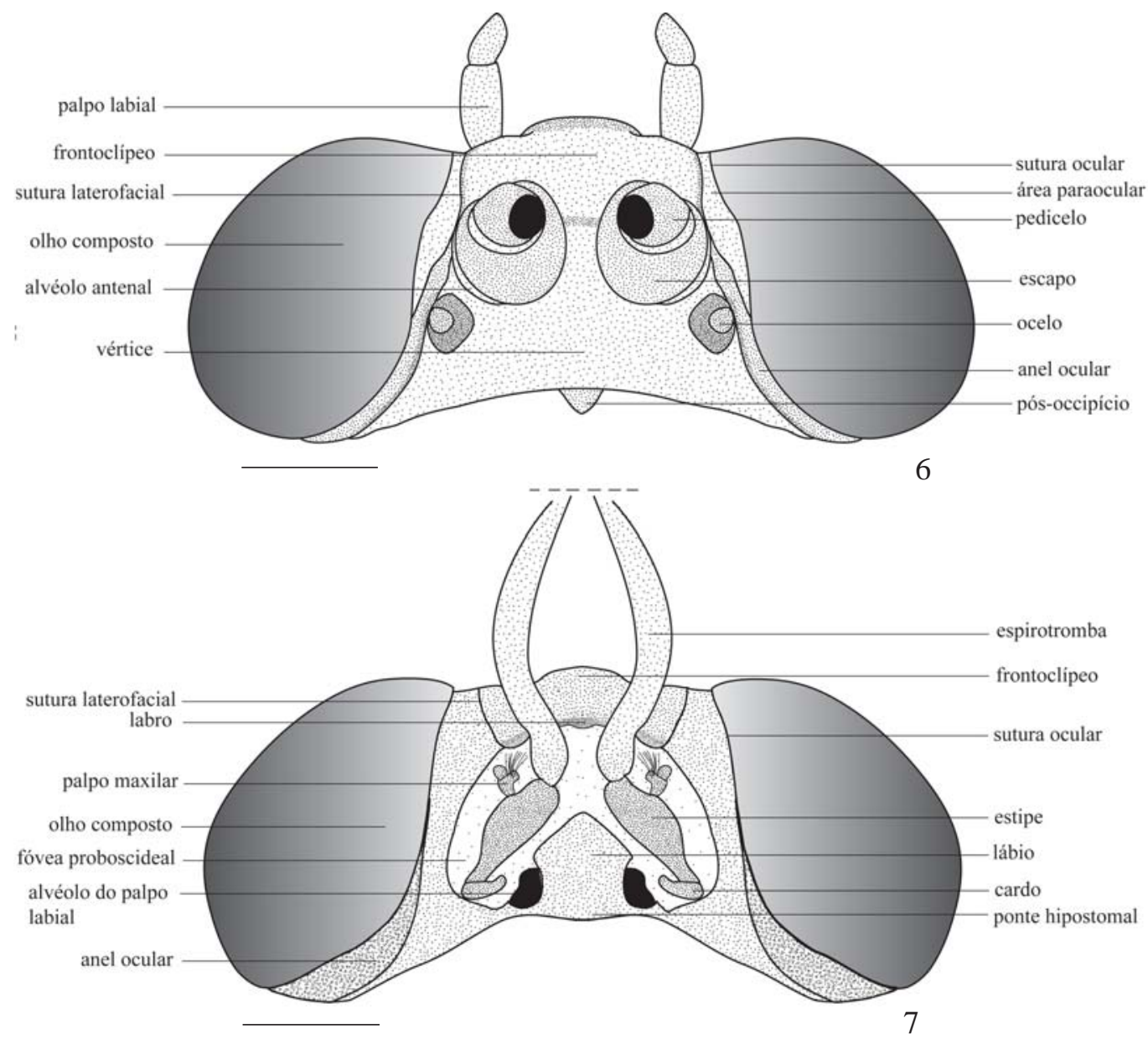

Figs. 6-7. Cabeça de T. licus (Drury). 6. Vista dorsal. 7. Vista ventral. Escala $=1 \mathrm{~mm}$.

contribuições gerais sobre morfologia de insetos (Snodgrass 1935; Matsuda 1965, 1970, 1976) e aos trabalhos de Mielke et al. (2004a, b, c), onde há discussões complementares sobre a morfologia de Lepidoptera. Com especial atenção à terminologia das genitálias masculina e feminina, onde é possível uma determinada estrutura ter sido descrita inúmeras vezes com diferentes nomes, dá-se prioridade às descrições originais das estruturas (ver genitália masculina de Lepidoptera em Pierce 1909; Sibatani et al. 1954; Okagaki et al. 1955; Ogata et al. 1957; Birket-Smith 1974; genitália feminina em Pierce 1914; Mutuura 1972).

\section{RESULTADOS EDISCUSSÃO}

Cabeça (Figs. 4-21). Hipognata e mais larga que longa nas três espécies do complexo T. licus. Em vista frontal, destacamse os olhos compostos grandes, glabros, com margem interna reta (Figs. 4, 8, 12).

Antenas clavadas e com apículo. Escapo e pedicelo distintos. Flagelômeros subcilíndricos, achatados gradualmente até a região da clava; último flagelômero estendido e com conjunto de sensilas (Figs. 16-18). Número de flagelômeros variando pouco entre as espécies: 61-66 flagelômeros em T. licus, 59-65 em T. syphax e 62-69 em $C$. atymnius.

Frontoclípeo subquadrangular, delimitado lateralmente pela sutura laterofacial, com origem no alvéolo antenal, mantendose paralela ao olho até encontrar, medianamente, a fóvea tentorial anterior; delimitado ventralmente pela sutura clipeolabral. Limite dorsal do frontoclípeo representado pela sutura transfrontal não evidente; nota-se, no entanto, uma zona mais esclerotizada entre os alvéolos antenais.

Labro situado ventralmente ao frontoclípeo, distinguindose pela presença da sutura clipeolabral; com duas projeções laterais cobertas de sensilas, os pilíferos, de função sensorial (Scoble 1992).

Sutura laterofacial paralela à margem do olho, desviandose medianamente no terço basal próximo da fóvea tentorial anterior, que é marcada pela inflexão do exoesqueleto, produzindo internamente o braço anterior do tentório, destinado à inserção de músculos cefálicos (Snodgrass 1935).

Sutura epistomal, geralmente localizada no limite ventral do frontoclípeo e unindo as extremidades anteriores das suturas subgenais (Snodgrass 1935), porém não identificada nas espécies aqui estudadas.

Palpo labial recurvado e triarticulado; artículo mediano, 

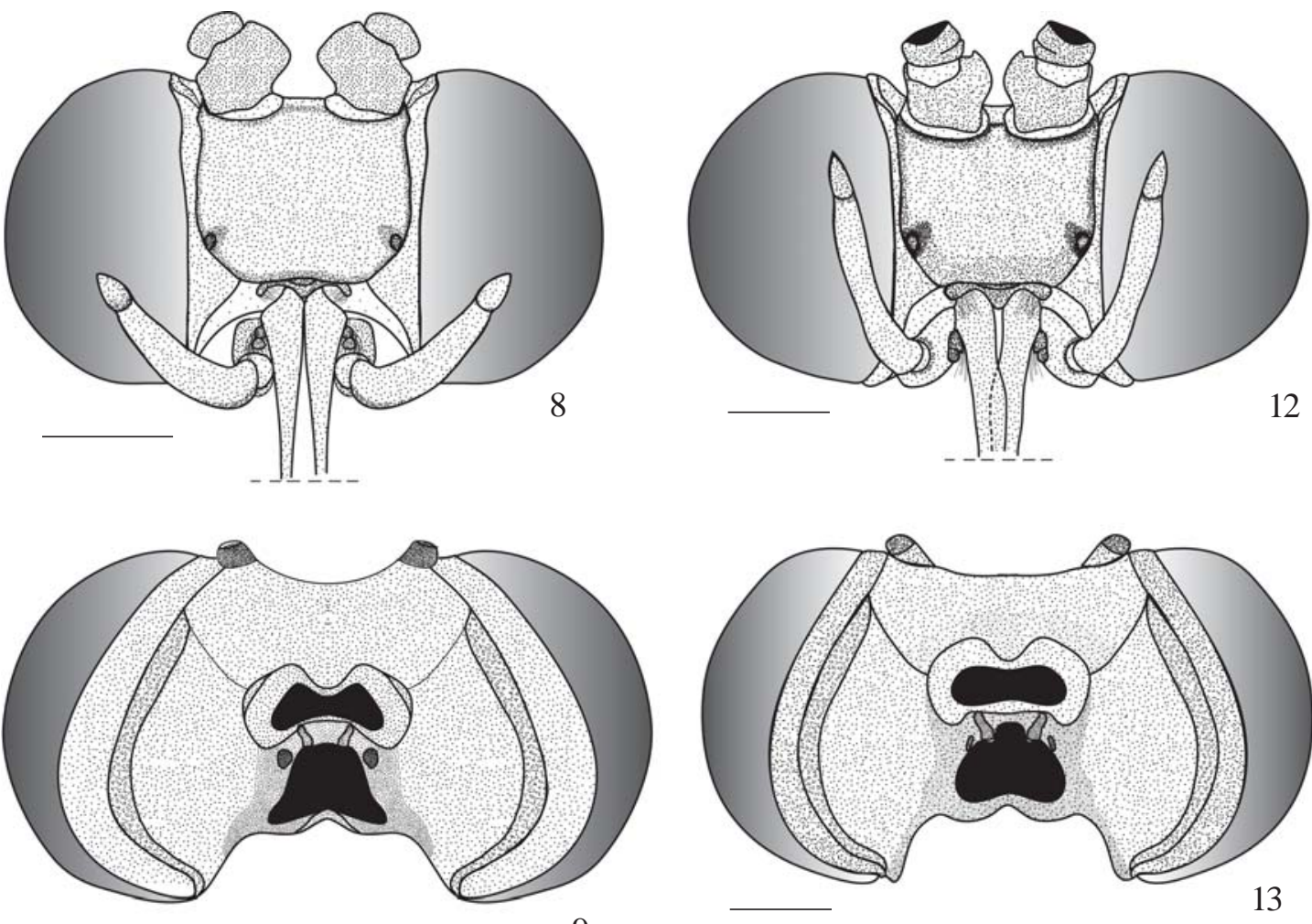

9
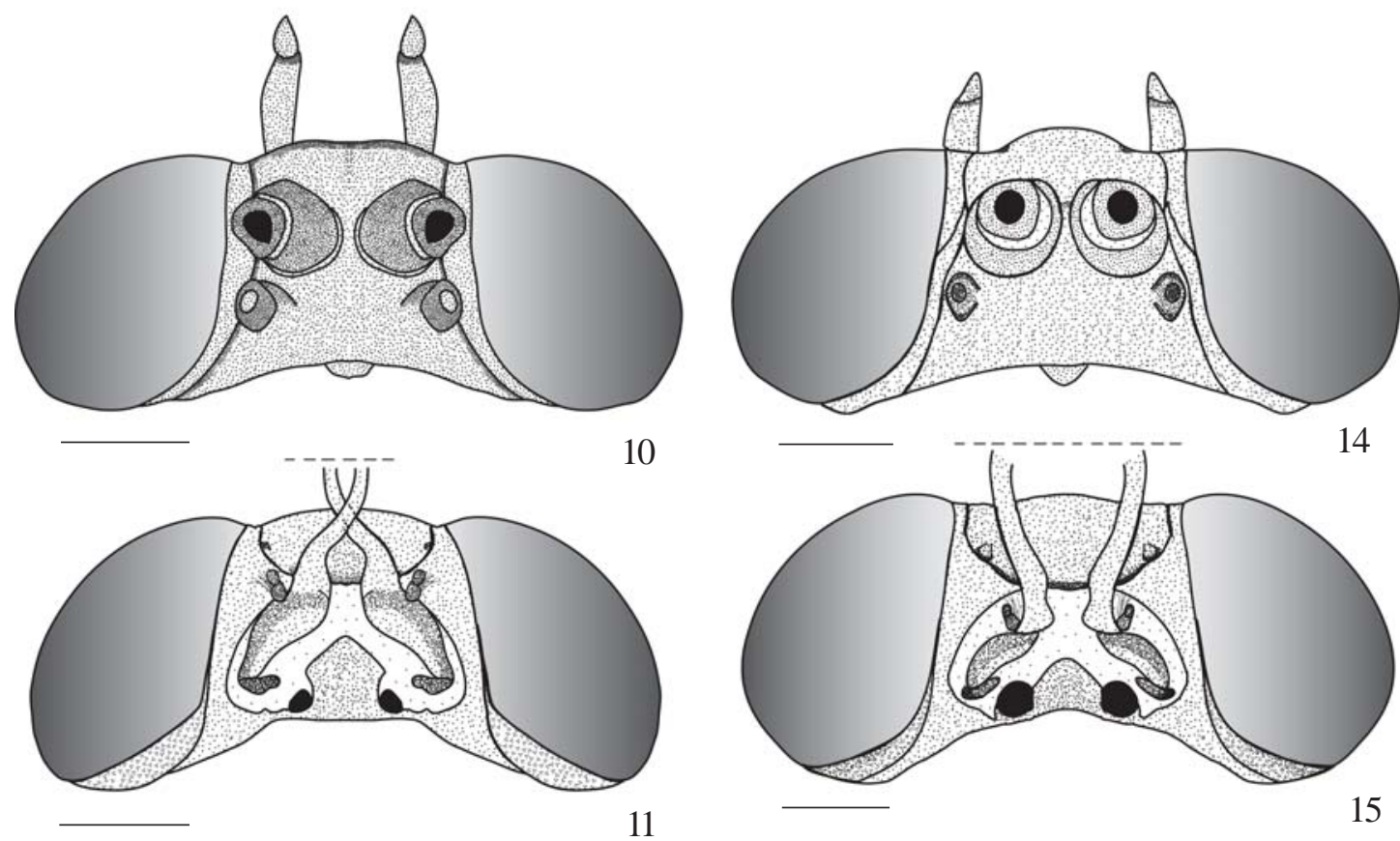

Figs. 8-15. Cabeça, vistas frontal, posterior, dorsal e ventral (cima para baixo). 8-11. T. syphax (Fabricius). 12-15. T. atymnius (Dalman) comb. nov. Escala $=1 \mathrm{~mm}$.

aproximadamente o dobro do comprimento do artículo basal e quase três vezes o do distal; mancha sensitiva basal (mancha de Reuter) com pequenos espinhos dispostos na superfície dorsal do articulo basal; órgão de vom Rath não evidente nas três espécies estudadas (Figs. 19-21).

Dorsalmente, antenas e ocelos destacados, notando-se a conexão entre a sutura laterofacial e a região anterior do alvéolo antenal (Figs. 6, 10, 14). Sutura transfrontal não evidente, mas com uma região ligeiramente mais esclerotizada demarcando o limite entre o esclerito clipeolabral e o vértice. Quetosema ausente nas três espécies.

Em vista ventral, peças bucais localizadas na fóvea 


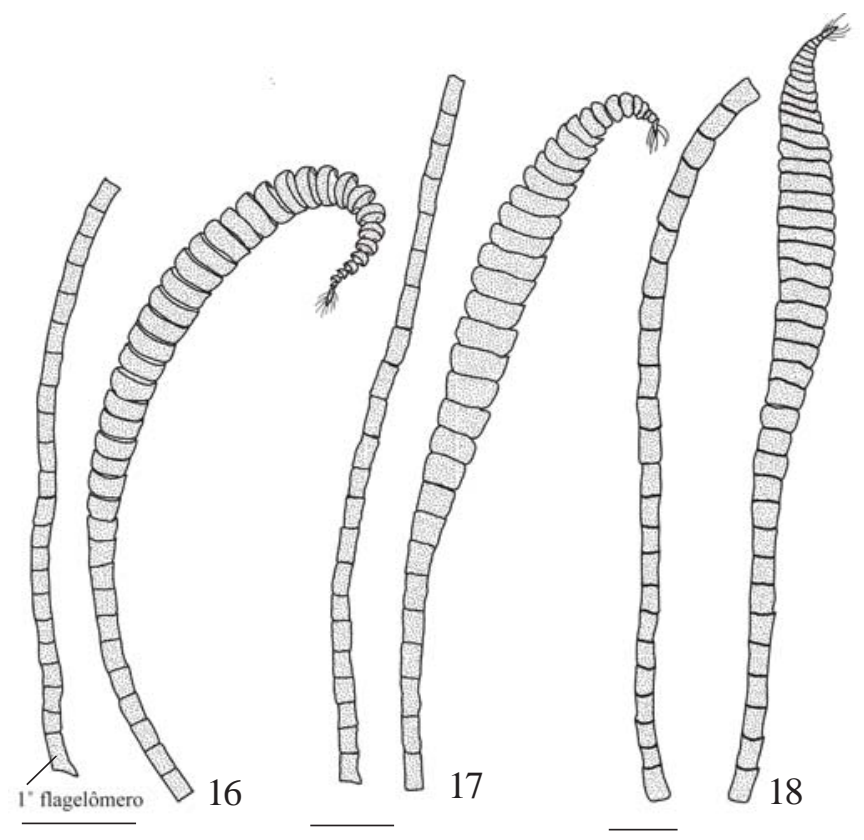

Figs. 16-18. Antena, vista lateral externa. 16. T. licus (Drury). 17. T. syphax (Fabricius). 18. T. atymnius (Dalman) comb. nov. Escala $=1$ $\mathrm{mm}$.

proboscideal, delimitada lateralmente pela região da subgena e anteriormente pelo labro (Figs. 7, 11, 15). Lábio ocupando a região central com formato de "ponta de seta" em T. licus e $T$. syphax (Figs. 7, 11), e com as margens arredondadas em $C$. atymnius (Fig. 15). Cardo e estipe nas laterais do lábio e logo acima deles o palpo maxilar biarticulado, com sensilas apenas no artículo basal. Limite entre o estipe e a espirotromba não totalmente demarcado em T. syphax, diferentemente de T. licus e C. atymnius. Distalmente à maxila, sutura subgenal levemente arqueada delimitando a região entre os olhos e a fóvea proboscideal.

Em vista posterior, forame magno dividido em uma abertura superior sub-retangular e outra inferior subtriangular (Figs. 5,
9, 13). Entre essas aberturas, na ponte pós-occiptal, côndilo cervical, ponto de articulação do esclerito cervical. Lateralmente ao côndilo, a fóvea tentorial posterior, produzindo internamente o braço posterior do tentório. Região de flanqueio dos forames superior e inferior com grau de esclerotização diferenciado nas três espécies (Figs. 5, 9, 13).

Sutura pós-occipital circundando a abertura superior do forame e delimitando o pós-occípcio (indicado de forma ambígua na Fig. 8 de Mielke et al. 2004a). Occipício (sensu Snodgrass 1935) ocupando a porção superior da cabeça em vista posterior; separado da pós-gena (sensu Snodgrass 1935) pela sutura temporal, levemente arqueada, percorrendo o limite inferior do occipício entre as suturas pós-occipital e ocular, às vezes ligeiramente mais destacada em T. syphax (Fig. 9).

Michener (1952), Ehrlich (1958, 1960) e Miller (1971) não fizeram distinção entre o occipício e a pós-gena, nomeando-as simplesmente como occipício ou área occipital. Sorensen (1980) também não fez tal distinção, mas empregou o termo área occipital + pós-gena para definir as duas regiões. Mielke et al. (2004a) seguiram a interpretação e a terminologia de Snodgrass (1935), enquanto que Camargo et al. (2005) usaram os termos pós-gena e área occipital em referência à mesma estrutura, a pós-gena (sensu Snodgrass 1935).

Lateralmente à região do occipício e acompanhando a curvatura do olho, estão as suturas transoccipital (interna) e ocular (externa), e entre elas, a banda transoccipital, de textura diferenciada. Lateralmente à banda transoccipital, o anel ocular, evidente em vista posterior, pouco desenvolvido dorsal e ventralmente e praticamente ausente em vista frontal; desenvolvido em outras espécies de Castniidae (Miller 1971).

Região cervical (Figs. 22-24). Região predominantemente membranosa, com um par de escleritos cervicais em forma de "L" deitado. O esclerito cervical articula-se com a região posterior da cabeça, no côndilo occipital, por meio do braço maior e com o protórax, no pré-esterno I, por meio do braço menor. Órgão cervical localizado na superfície ventral do braço maior (Figs. 22-24). A morfologia do esclerito não variou nas espécies estudadas, entretanto mostrou-se com ângulos mais
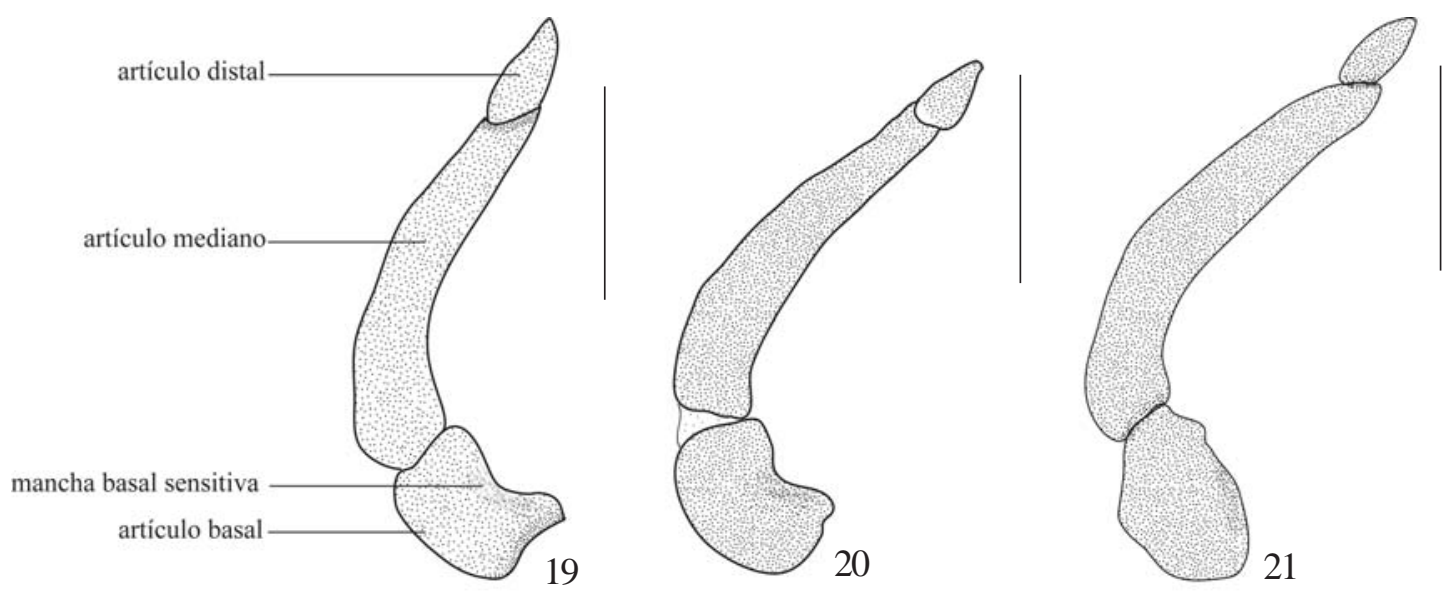

Figs. 19-21. Palpo labial, vista lateral externa. 19. T. licus (Drury). 20. T. syphax (Fabricius). 21. T. atymnius (Dalman) comb. nov. Escala $=1$ mm. 


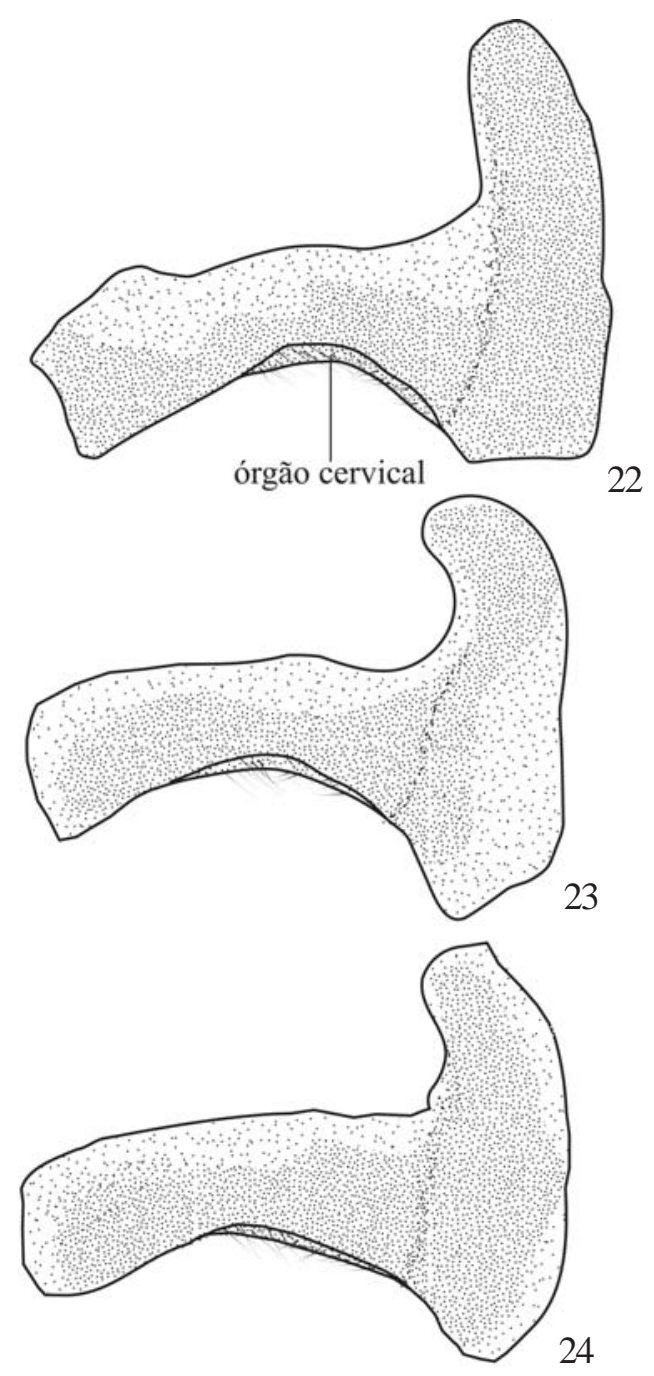

Figs. 22-24. Esclerito cervical, vista lateral externa. 22. T. licus (Drury). 23. T. syphax (Fabricius). 24. T. atymnius (Dalman) comb. nov. Escala $=1 \mathrm{~mm}$.

arredondados e porções menos escletorizadas em $T$. syphax (Fig. 23).

Tórax (Figs. 25-57). Protórax (Figs. 25-33). Membranoso e proporcionalmente menor que os demais segmentos torácicos. Para Snodgrass (1935), parte dos elementos esclerotizados presentes no protórax foram perdidos no processo de membranização da região cervical, formada pelos elementos estruturais da cabeça e do protórax.

Em vista dorsal, tergo protorácico muito semelhante nas três espécies (Figs. 28, 30, 32). Constituído por uma placa losangular com a metade inferior estendida até o pré-escuto II. Placa pronotal com ângulos mais agudos em T. licus e T. syphax do que em C. atymnius (Figs. 28, 30, 32); nesta placa nota-se ainda um sulco típico de Castniidae ("trough-spaped tergum" sensu Edwards et al. 1998). Patágios e parapatágios pouco esclerotizados e em forma de vesícula, dispostos paralelamente entre si e marginalmente em relação ao tergo protorácico, estendendo-se lateralmente no protórax. Parapatágios mais delgados que os patágios (Figs. 25-27).

Em vista lateral, placa lateral do pronoto articulada dorsalmente com o pronoto e em sua porção mais ventral com a pleura por meio da articulação pronoto-pleural (Figs. 25-27). Episterno I destacando-se entre os escleritos pleurais. Epimero I não evidente como em outras espécies de Lepidoptera (ver exemplos em Snodgrass 1935; Madden 1944; Mielke et al. 2004b; Duarte 2007).

Pré-esterno I em forma de "T". Episterno I articulando-se com os "braços" do pré-esterno. Basisterno conectado em sua porção anterior com o episterno (Figs. 29, 31, 33).

Mesotórax (Figs. 25-33). O mais desenvolvido dos três segmentos torácicos, com três escleritos notais: pré-escuto pouco conspícuo, escuto e escutelo bem definidos (Figs. 28, 30, 32).

Pré-escuto projetado ventralmente, pouco visível a não ser por transparência ou através da sutura pré-escuto-escutal (Matsuda 1970) em vista dorsal; articulado anteriormente com o pronoto e posteriormente com o escutelo, margens laterais estendidas lateralmente formando os braços pré-alares. Diferentemente do reportado para a maioria dos Ditrysia (Sharplin 1963), braços pré-alares livres ao invés de fusionados com a subtégula e o apódema tergopleural (Figs. 25-27).

Escuto de formato sub-retangular, o maior esclerito do mesotórax (Figs. 28, 30, 32). Delimitado anteriormente pela sutura pré-escuto-escutal e posteriormente pela sutura escutoescutelar. Linha mesoescultal incompleta. Tégula em forma de colchete, na margem lateral da região anterior do escuto, com dois processos: um dorsal proeminente sobre a asa anterior e outro ventral, menor, alojado sob a asa anterior. Subtégula semilunar, fundida e sustentada em sua região posterior pelo apódema tergopleural.

Tabela I. Número de exemplares dissecados de cada espécie do complexo Telchin licus com as localidades de coleta, quando disponíveis.

\begin{tabular}{|c|c|c|c|}
\hline Espécies & Material sem procedência & Material com procedência & Total \\
\hline Telchin licus & $50^{x} 0^{x}$ e 1 ㅇ & $\begin{array}{l}1 \text { ơ e } 1 \text { \&: Itacoatiara, AM, xii.1960, } 1962 \text { (genitálias dissecadas) } \\
1 \text { ㅇ: São Paulo de Olivença, AM, sem data (genitália dissecada) }\end{array}$ & 9 \\
\hline Telchin syphax & $40^{x} o^{x}$ e 1 ㅇ & 1 ơ e 2 우: Óbidos, PA, x.1938, sem data, xii.1961 (genitálias dissecadas) & 8 \\
\hline $\begin{array}{l}\text { Telchin atymnius } \\
\text { comb. nov. }\end{array}$ & 1 우 & $\begin{array}{l}2 \text { ơ }^{\pi}: \text { Camacã, BA, ii.2007, 800m, M. Duarte col. (um exemplar inteiramente } \\
\text { dissecado, outro apenas genitália) } \\
1 \sigma^{\star}: \text { Peruíbe, SP, ii.1972 (genitália dissecada) } \\
1 \text { or: São Paulo, SP, sem data (genitália dissecada) }^{\star} \text {. }\end{array}$ & 5 \\
\hline
\end{tabular}




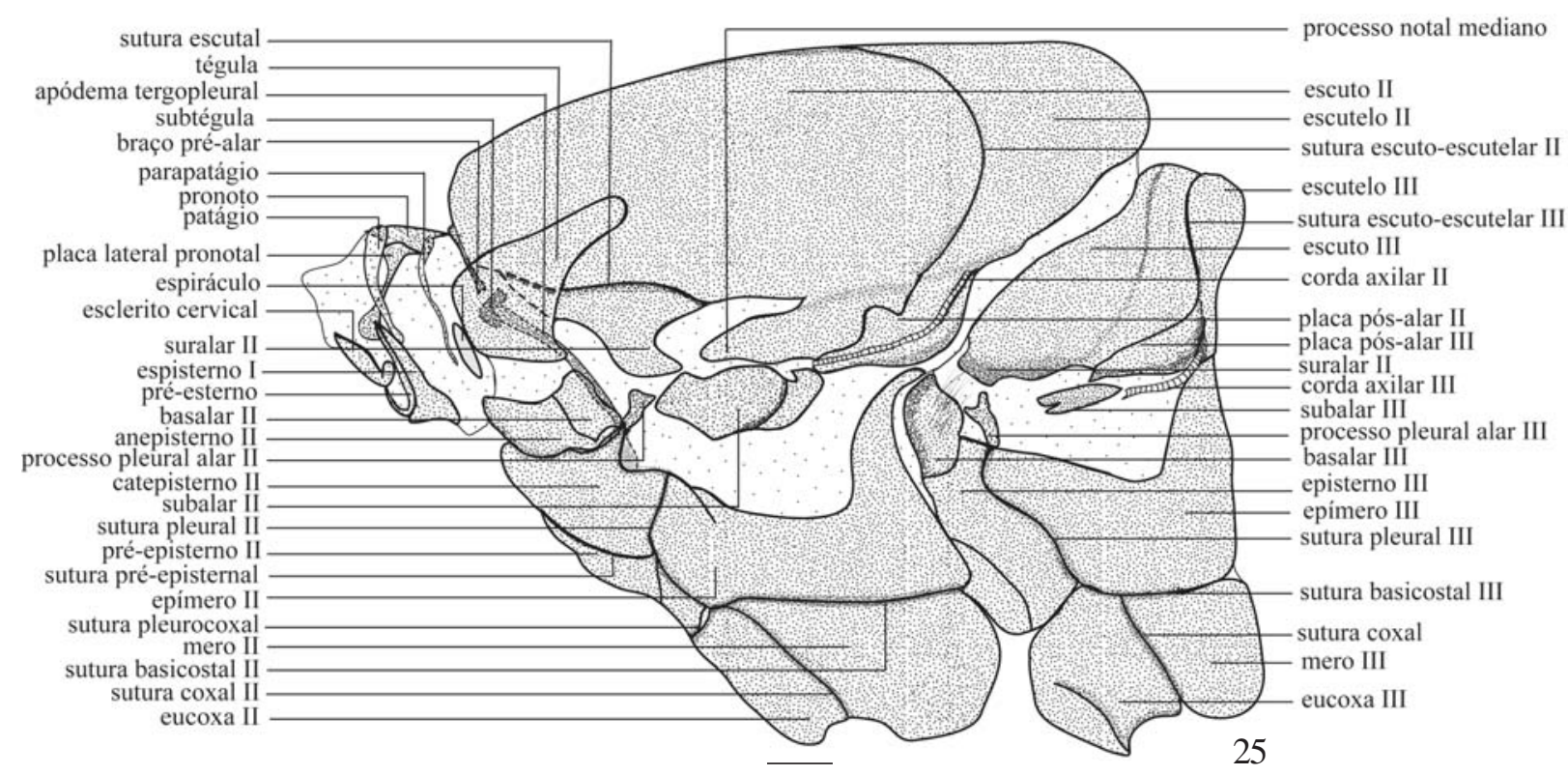

Fig. 25. Tórax de T. licus (Drury), vista lateral. Escala $=1 \mathrm{~mm}$.

Escutelo tão largo quanto longo, com margem anterior proeminente formando uma lança, margem posterior arredondada; sustentando a corda axilar contígua à margem posterior da placa pós-alar.

Margens laterais do escuto e do escutelo com três processos de articulação com as asas. Processos notais anterior e mediano localizados no escuto; processo notal posterior localizado no escutelo (os três processos com uma série de sinonímias: ver Snodgrass 1935; Madden 1944; Matsuda 1970; Sorensen 1980).

Processo notal anterior localizado no esclerito suralar facilmente reconhecido pela região anterior afilada, encoberta pela tégula, e pela região posterior falciforme. Processo notal mediano ("adnotale" sensu Madden 1944) projetado pósterolateralmente em direção à suralar. Processo notal posterior ("adanale" sensu Madden 1944) localizado na placa pós-alar ("adanale" + "postadanale" sensu Madden 1944), definida como uma extensão lateral do escutelo encobrindo parcialmente o processo notal mediano.

Em vista lateral, identificados dois escleritos pleurais (epipleuritos sensu Snodgrass 1935) servindo como pontos de inserção para a musculatura alar através de projeções internas ou apódemas (Figs. 25-27): basalar, o anterior, adjacente ao processo pleural alar e parcialmente fundido ao anepisterno I; subalar subtrapezoidal, composto por duas placas (Matsuda 1970), imerso na pleura e em posição posterior ao processo pleural alar e logo acima do epimero II.

Sutura pleural localizada entre o episterno e o epimero, originando em sua porção dorsal o fulcro ou processo pleural alar, atuando como ponto de apoio para a asa (Figs. 25-27).

Episterno dividido pela sutura anepisternal em uma porção dorsal (anepisterno) e outra ventral (infraepisterno). Infraepisterno dividido pela sutura pré-episternal em duas regiões: uma anterior, o pré-episterno II (prepecto sensu Snodgrass 1935) fusionado ao basisterno; outra posterior, o catepisterno. Epimero como um único esclerito.

Para as três espécies estudadas não foram encontradas diferenças significativas nesse segmento torácico.

Metatórax (Figs. 25-33). Constituído das mesmas estruturas do mesotórax, embora algumas morfologicamente diferenciadas.

Tabela II. Comprimento e largura $(\mathrm{mm})$ das asas anteriores e posteriores das espécies do complexo Telchin licus.

\begin{tabular}{|c|c|c|c|c|c|}
\hline \multirow[b]{2}{*}{ Espécies } & & \multicolumn{2}{|c|}{ Asa anterior } & \multicolumn{2}{|c|}{ Asa posterior } \\
\hline & & $\begin{array}{c}\text { Comprimento } \\
\text { (base da asa até } \mathrm{R}_{3} \text { ) } \\
\mathrm{X} \pm \mathrm{SD}\end{array}$ & $\begin{array}{c}\text { Largura } \\
\left(\mathrm{R}_{3} \text { até } 2 \mathrm{~A}\right) \\
\mathrm{X} \pm \mathrm{SD}\end{array}$ & $\begin{array}{c}\text { Comprimento(base } \\
\text { da asa até veia) } \\
\mathrm{X} \pm \mathrm{SD}\end{array}$ & $\begin{array}{c}\text { Largura }\left(\mathrm{Sc}+\mathrm{R}_{1}\right. \\
\text { até } 3 \mathrm{~A}) \\
\mathrm{X} \pm \mathrm{SD} \\
\end{array}$ \\
\hline Telchin licus & $\sigma^{x}(n=13)$ & $42,38 \pm 3,45$ & $29,94 \pm 2,91$ & $33,72 \pm 2,16$ & $30,31 \pm 2,08$ \\
\hline & 우 $(\mathrm{n}=7)$ & $46,99 \pm 4,80$ & $33,16 \pm 4,97$ & $38,65 \pm 3,19$ & $33,94 \pm 4,78$ \\
\hline Telchin syphax & $\sigma^{x}(n=6)$ & $46,08 \pm 4,41$ & $32,40 \pm 3,00$ & $36,21 \pm 3,71$ & $33,02+4,62$ \\
\hline & 우 $(\mathrm{n}=4)$ & $47,83 \pm 3,90$ & $35,47 \pm 4,24$ & $38,65 \pm 3,09$ & $35,19+4,45$ \\
\hline Telchin atymnius & $\sigma^{x}(n=9)$ & $44,88 \pm 2,27$ & $31,31 \pm 1,62$ & $36,61 \pm 1,00$ & $32,03 \pm 2,06$ \\
\hline comb. nov. & 우 $(\mathrm{n}=1)$ & 49,65 & 35,60 & 41,05 & 36,46 \\
\hline
\end{tabular}



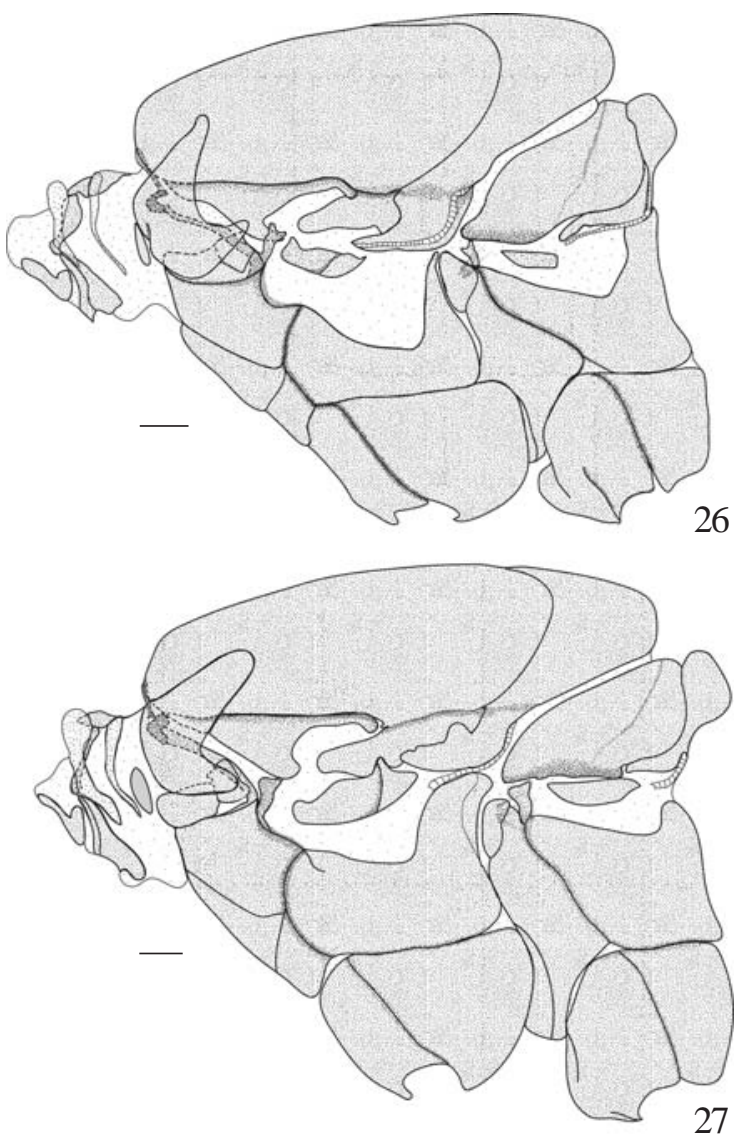

Figs. 26-27. Tórax, vista lateral. 26. T. syphax (Fabricius). 27. T. atymnius (Dalman) comb. nov. Escala $=1 \mathrm{~mm}$.

Em vista dorsal, escuto III definido como dois escleritos sub-retangulares acompanhando as laterais do escutelo II (Figs. 28, 30, 32). Em vista lateral, margem ântero-ventral com uma região distintamente esclerotizada demarcando a região da suralar, porém desprovida da sutura escutal. Processo notal mediano não encontrado.

Escutelo III elipsoidal em vista dorsal e lateralmente representado pela placa pós-alar III, com a extremidade anterior desenvolvida no processo notal posterior. Placa pós-alar III projetada anteriormente, margem posterior contígua à corda axilar (Figs. 25-27).

Região pleural frequentemente objeto de conflito entre os autores, principalmente no que concerne à nomenclatura de seus escleritos (Shepard 1930; Madden 1944; Ehrlich 1958, Sorensen 1980).

Madden, em trabalho de 1944, não apresenta divisão do episterno metatorácico em anepisterno e catepisterno. $\mathrm{O}$ autor define na porção dorsal do episterno uma estrutura subcircular: a almofada do basalar ("basalar pad" sensu Shepard 1930) e logo acima dessa estrutura o esclerito basalar. A principal diferença entre as interpretações da almofada basalar apresentadas por Shepard (1930) e Madden (1944) está na presença de cerdas mencionadas pelo primeiro autor. Ehrlich (1958) denomina anepisterno uma estrutura com posição e

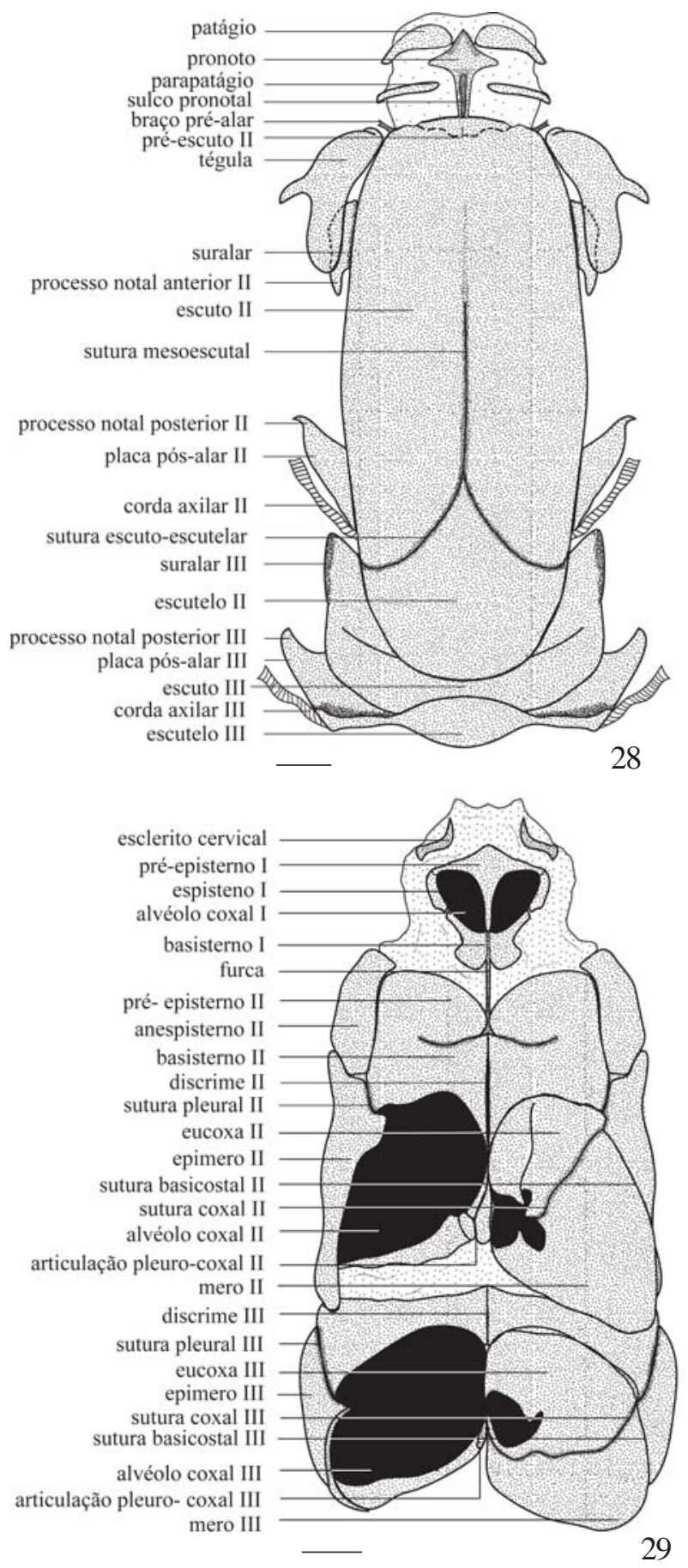

Figs. 28-29. Tórax de T. licus (Drury). 28. Vista dorsal. 29. Vista ventral. Escala $=1 \mathrm{~mm}$.

morfologia muito similar à almofada do basalar descrita por Shepard (1930). Finalmente, Sorensen (1980) constata no metatórax a presença de um anepisterno reduzido e fundido ântero-ventralmente com o infraepisterno e um esclerito basalar tripartido. Nas espécies estudadas no presente trabalho, a estrutura subcircular presente na porção dorsal do episterno metatorácico se assemelha à estrutura descrita por Shepard (1930) e Madden (1944), inclusive com as cerdas sensoriais 

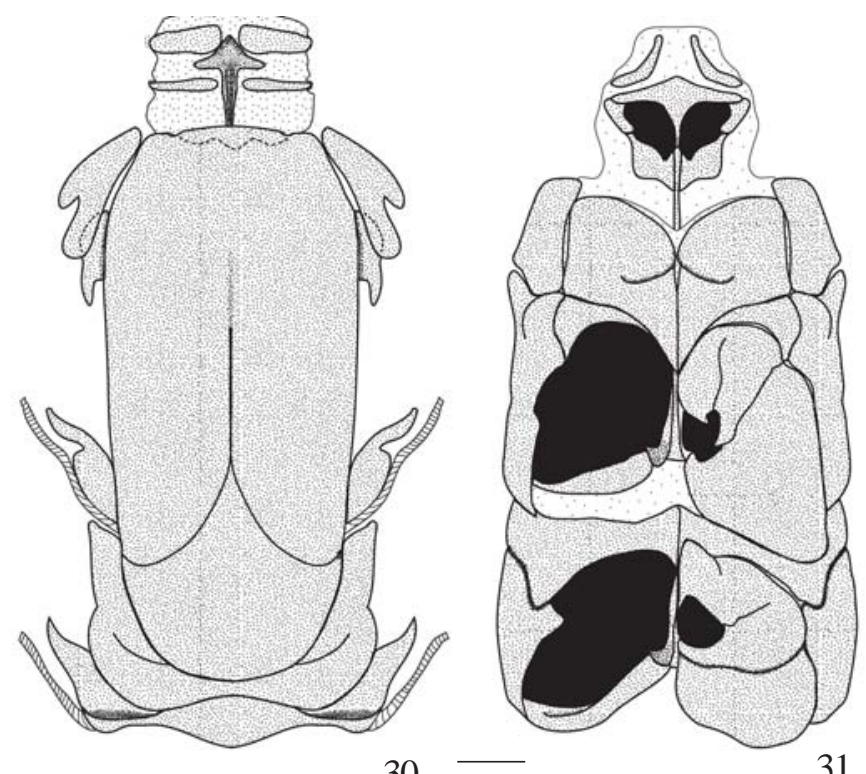

30

31
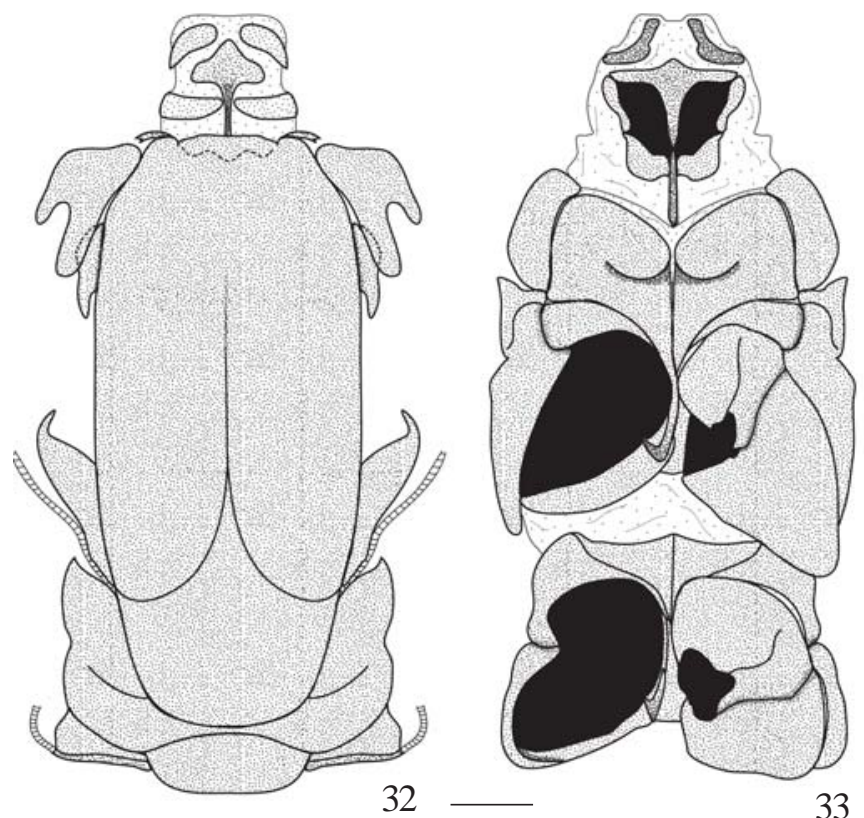

33

Figs. 30-33. Tórax, vistas dorsal e ventral (esquerda para direita). 3031. T. syphax (Fabricius). 32-33. T. atymnius (Dalman) comb. nov. Escala $=1 \mathrm{~mm}$.

supracitadas. Contudo, optou-se pelo termo basalar ao invés de almofada do basalar, pois a disposição do esclerito em relação às estruturas adjacentes sugere que ele seja serialmente homólogo ao esclerito basalar do mesotórax (homologia primária sensu de Pinna 1991).

No metatórax, a diferença mais notável observada entre as espécies aqui estudadas é o formato do esclerito basalar. Em T. licus e T. syphax, esse esclerito possui formato ovalado; em C. atymnius, o esclerito é mais estreito e alongado (Figs. 2527).

Pernas (Figs. 34-51). Entre T. licus, T. syphax e C. atymnius, a proporção dos artículos das pernas, o tamanho e a distância dos esporões tibiais e o tamanho da epífise são bastante semelhantes (Figs. 34-42), não fornecendo nenhum caráter para rápida identificação das espécies. Entretanto, Houlbert (1918) desenvolveu um sistema de classificação para Castniidae envolvendo diferenças morfológicas dos componentes do último tarsômero. De forma semelhante, Miller (1986) fez uso de caracteres morfométricos de alguns artículos das pernas para caracterizar gêneros dentro de Castniidae.

Estruturas terminais do último tarsômero variam entre os segmentos torácicos e entre as espécies (Figs. 43-51). Dimorfismo sexual distinto. Na fêmea, pulvilos semelhantes nos três pares de pernas. No macho, pulvilos das pernas protorácicas e metatorácicas como na fêmea, porém o da perna mesotorácica com tufos de cerdas na extremidade distal (Figs. 46-48). Esses tufos de cerdas estão presentes também em outras espécies de Castniidae e podem estar relacionados com a dispersão de componentes voláteis produzidos pelas androcônias abdominais (Jordan, 1923), porém, no presente estudo, nenhuma das três espécies estudadas apresenta estrutura abdominal semelhante a androcônias. A disposição das cerdas no pulvilo varia significativamente entre as espécies. Em T. lycus, as cerdas são abundantes e estão reunidas em forma de pincel (Fig. 46); em T. syphax (Fig. 47) e C. atymnius (Fig. 48), estão dispersas e não formam pincel, porém observa-se uma distribuição menos aleatória das cerdas em C. atymnius.

Placa unguitratora e arólio com pequenas variações nos contornos entre os segmentos torácicos e entre as espécies estudadas (Figs. 43-51).

Asas (Figs. 52-57). Asa anterior subtriangular, com margem externa reta (Figs. 52-54). Asa posterior oval de contornos arredondados (Figs. 55-57). Telchin licus, T. syphax e $C$. atymnius com comprimento e largura das asas, em média, maiores nas fêmeas (Tab. II), alguns machos, no entanto, com medidas alares maiores que das fêmeas. Macho com frênulo constituído de uma única cerda; retináculo formado por uma expansão da veia subcostal; fêmea com tufo de cerdas e escamas diferenciadas no lugar do frênulo e retináculo, respectivamente.

Asa anterior com 14 veias longitudinais estendendo-se até a margem externa, com exceção da veia 3A (Figs. 52-54). Veia subcostal livre desde a base e sem ramificação, percorrendo cerca de dois terços da margem costal. Radial constituída por cinco ramos. Veias médias com três ramos: $\mathrm{M}_{1}$ originando-se próximo à $R_{5}$ e $M_{2}$ mais próxima de $M_{3}$ do que de $\mathrm{M}_{1}$. Cubital com três ramos: $\mathrm{CuA}_{1}$ originando-se próximo de $\mathrm{M}_{3}$, a partir do ápice da célula acessória localizada logo abaixo da célula discal: $\mathrm{CuA}_{2}$ mais próxima de $\mathrm{CuA}_{1}$ do que da $\mathrm{CuP}$. Duas veias anais: $2 \mathrm{~A}$ e $3 \mathrm{~A}$.

Célula discal alcançando metade do comprimento da margem costal, corda formada pela união de $\mathrm{R}_{3}$ e $\mathrm{R}_{4}$; duas células acessórias, uma logo abaixo da célula discal, fechada pela veia transversal $\mathrm{m}_{3}$-cua , outra próxima da base, fechada pela veia transversal 2a-3a (Figs. 52-54).

Asa posterior com nove veias longitudinais, todas alcançando a margem externa (Figs. 55-57). Subcostal fundida 


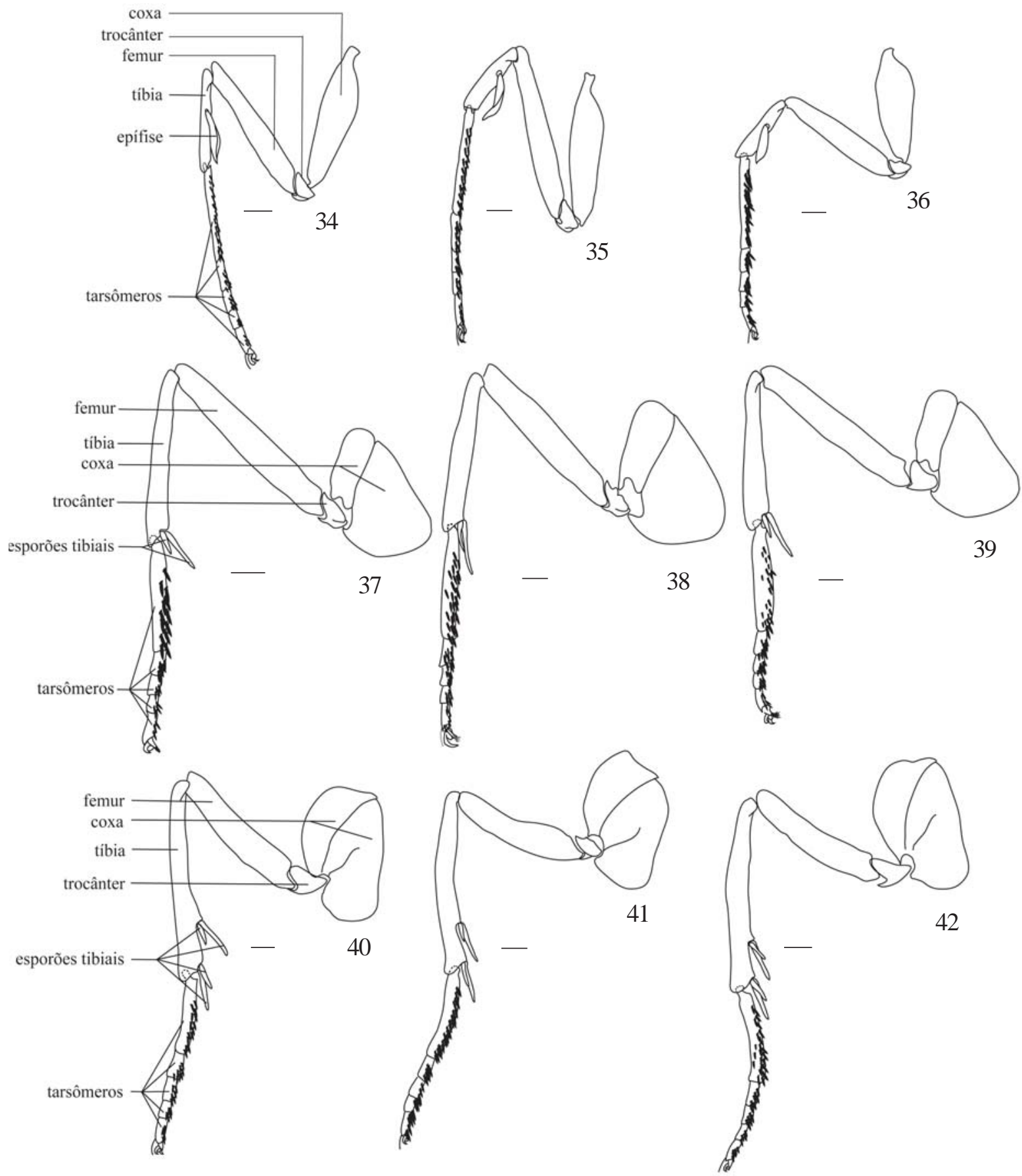

Figs. 34-42. Pernas de T. licus (Drury), T. syphax (Fabricius) e T. atymnius (Dalman) comb. nov. (esquerda para direita), vista lateral externa. 3436. Pernas protorácicas. 37-39. Pernas mesotorácicas. 40-42. Pernas metatorácicas. Escala $=1 \mathrm{~mm}$.

à $R_{1}$. Setor radial em forquilha com $M_{1}$. Célula discal aberta. $M_{2}$ ausente (Miller, 1986). Veias $\mathrm{M}_{3}, \mathrm{CuA}_{1}, \mathrm{CuA}_{2}$ e CuP partindo da célula acessória, fechada pela veia transversal cua1-cua2. Anal com dois ramos, 2A e $3 \mathrm{~A}$, ambos alcançando a margem externa da asa (Figs. 55-57).

Abdome (Figs. 58-63). Macho e fêmea com abdome cônico e segmentos telescopados (Figs. 58-63). No macho, apenas oito segmentos visíveis, sendo o nono e décimo retraídos no oitavo (Figs. 58, 60, 62) e modificados na formação da genitália masculina. Na fêmea, apenas os sete primeiros segmentos visíveis externamente (Figs. 59, 61, 63); os demais, interiorizados na porção posterior do abdome e modificados na formação da genitália.

Primeiro segmento abdominal de ambos os sexos com adaptações morfológicas relacionadas às articulações torácico-abdominais. Esterno I ausente. Tergo I reduzido em relação aos demais segmentos; margem laterais com uma placa sulcada em toda sua extensão (fenda tergo-pleural sensu Forbes 

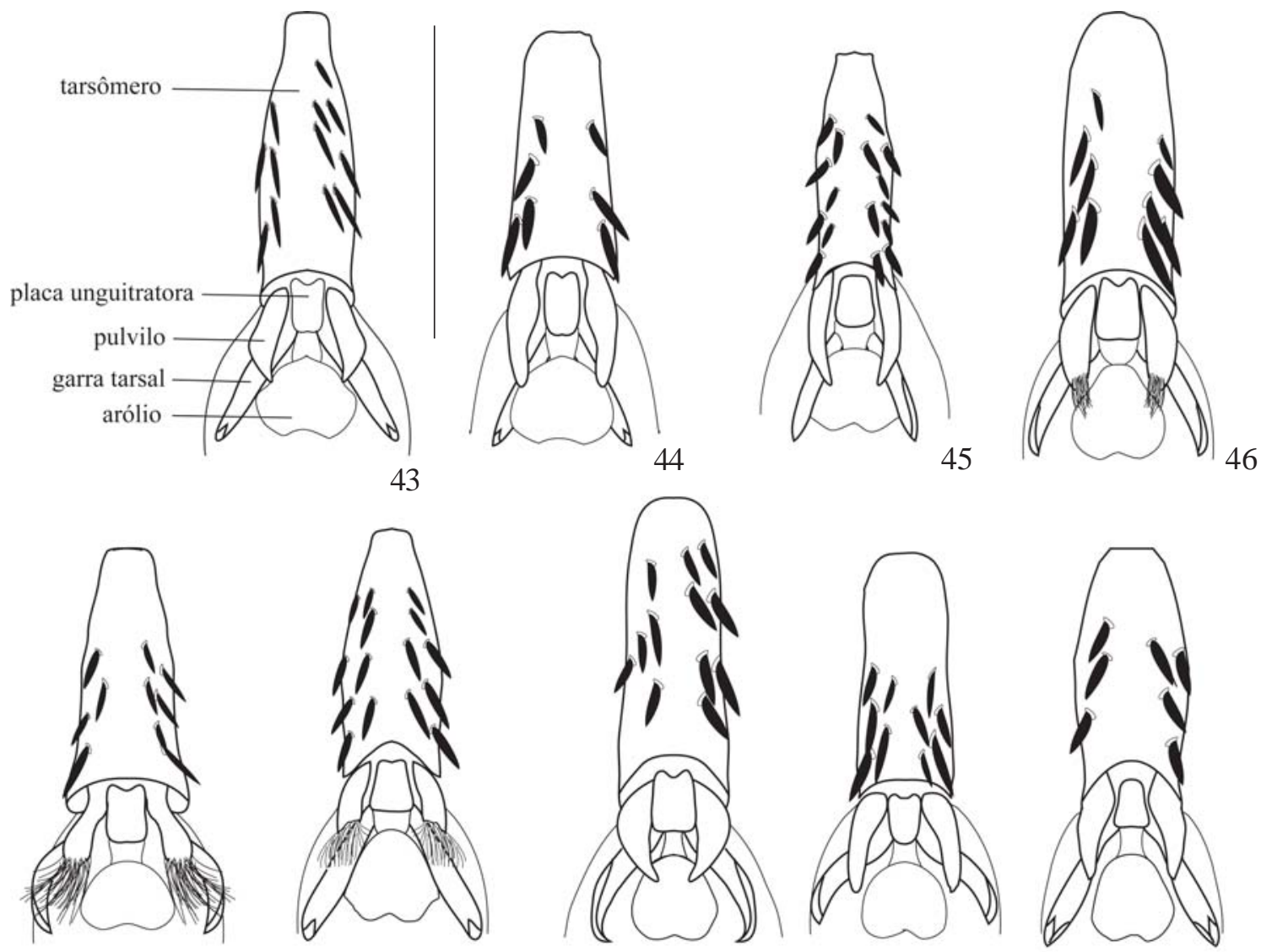

47

48

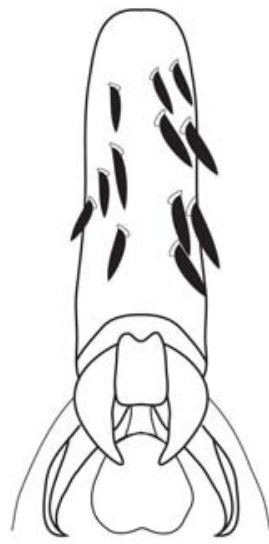

49

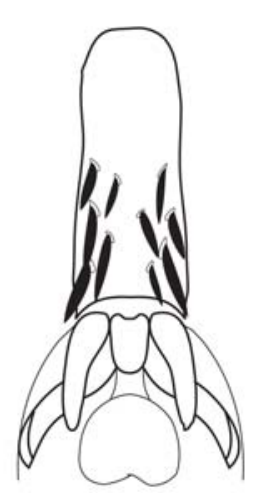

50

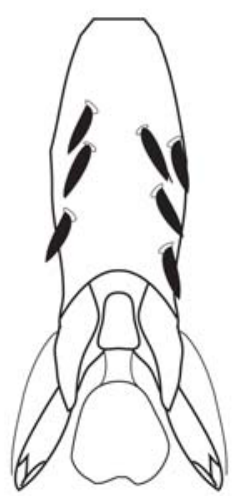

51

Figs. 43-51. Último tarsômero das pernas pro, meso e metatorácicas, vista ventral. 43-45. T. licus (Drury). 46-48. T. syphax (Fabricius). 49-51. T. atymnius (Dalman) comb. nov. Escala $=1 \mathrm{~mm}$.
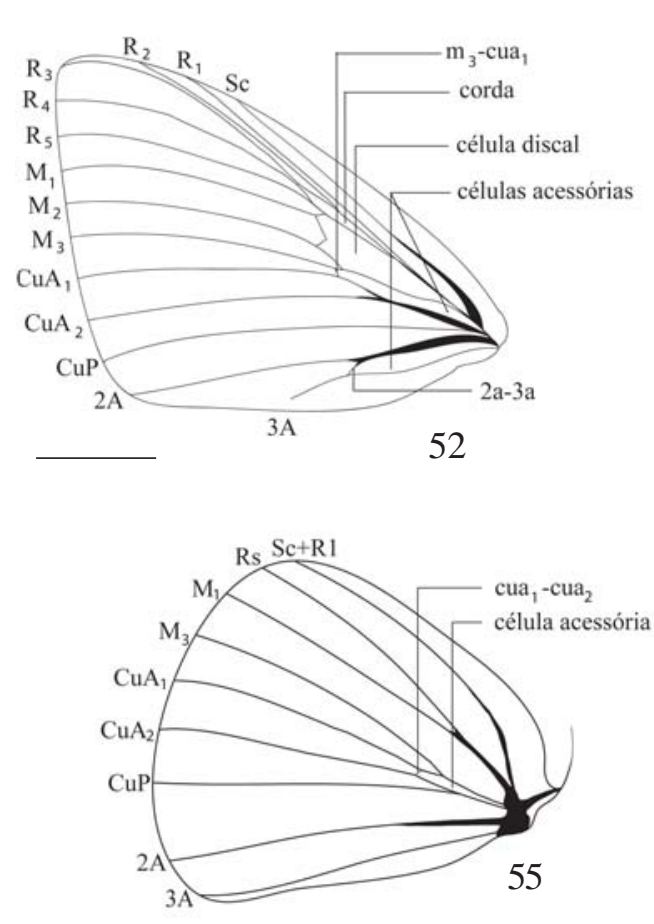
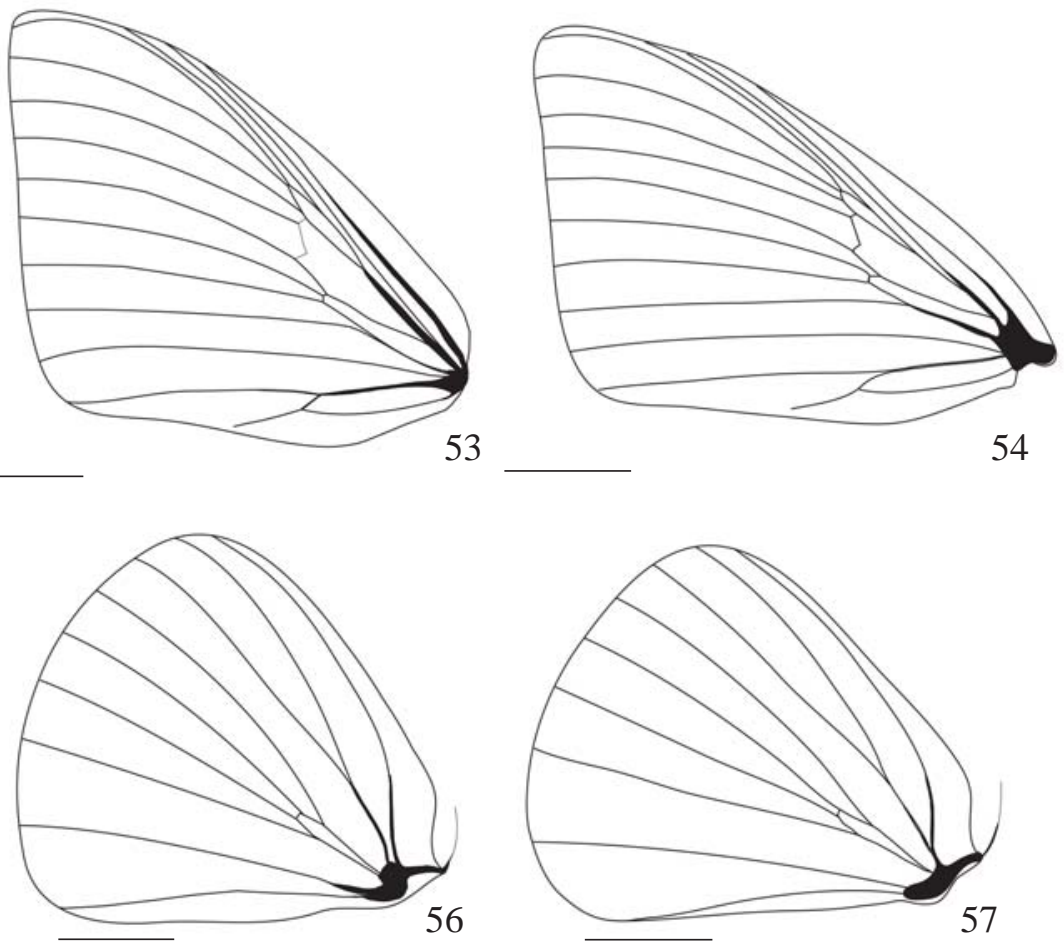

Figs. 52-57. Asas anterior e posterior. 52, 55. T. licus (Drury). 53, 56. T. syphax (Fabricius). 54, 57. T. atymnius (Dalman) comb. nov. Escala = $1 \mathrm{~cm}$. 

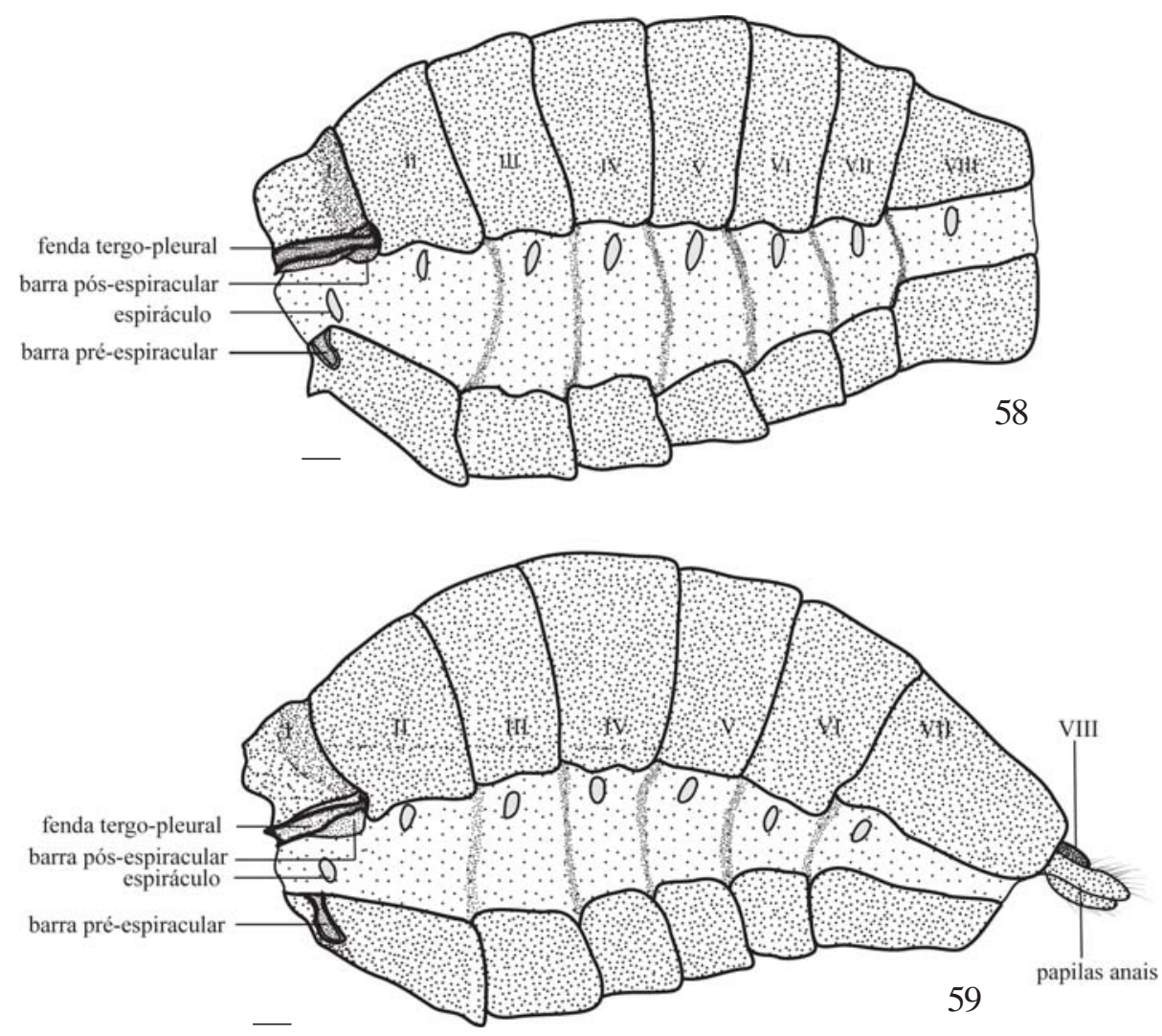

Figs. 58-59. Abdome de T. licus (Drury), vista lateral. 58. Macho. 59. Fêmea. Escala $=1 \mathrm{~mm}$.
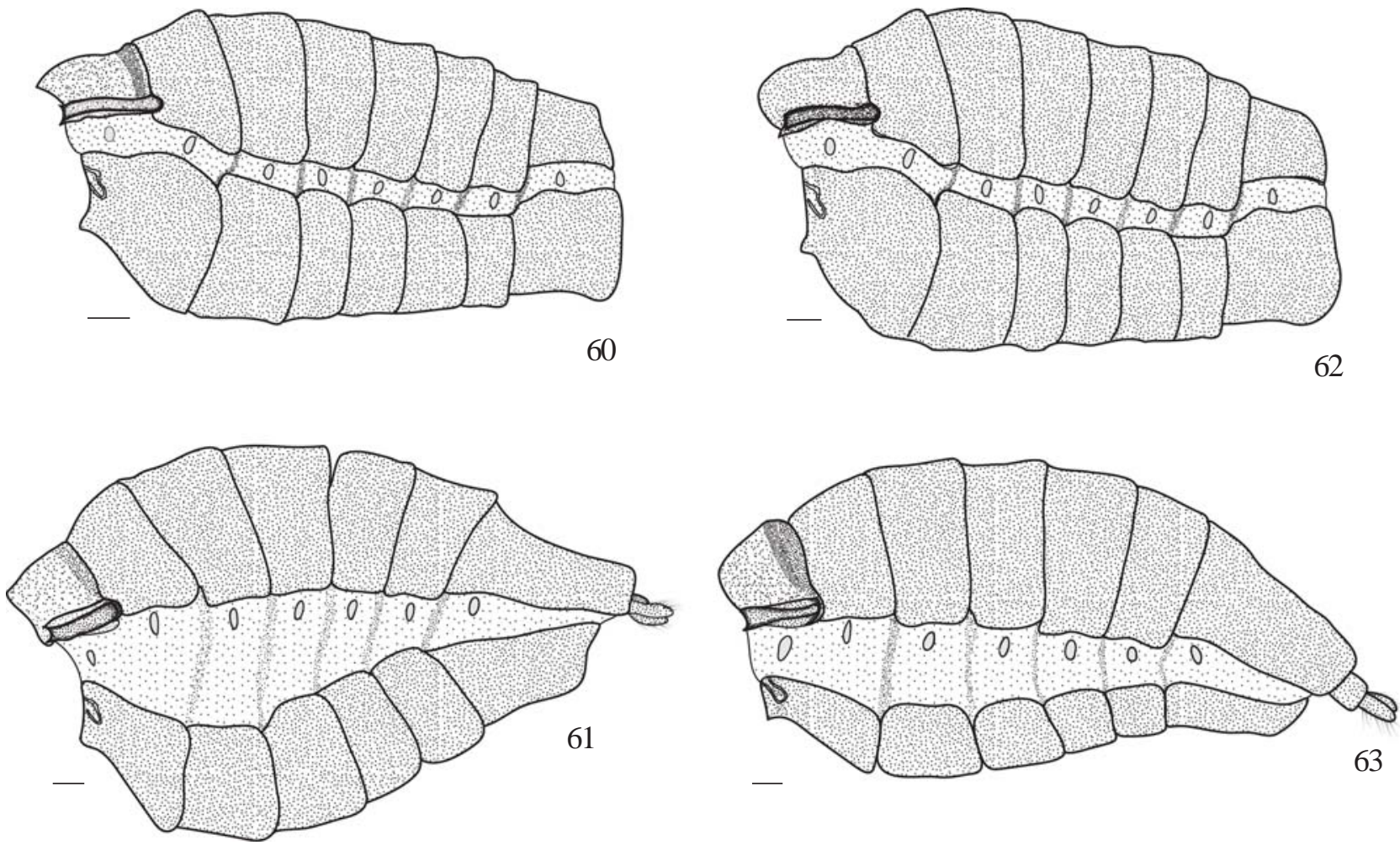

Figs. 60-63. Abdome, macho e fêmea, vista lateral. 60-61. T. syphax (Fabricius). 62-63. T. atymnius (Dalman) comb. nov. Escala = 1 mm. 


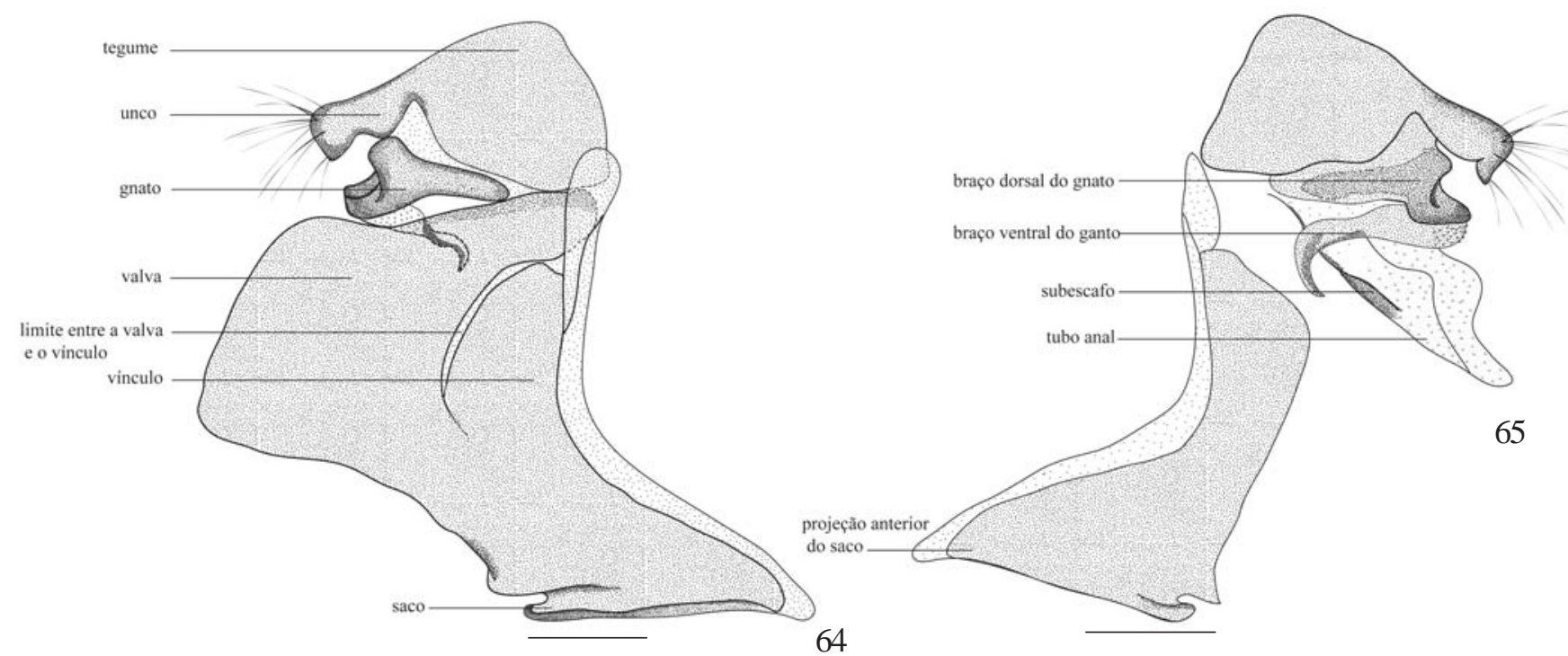

Figs. 64-65. Genitália masculina de T. licus (Drury). 64. Vista lateral esquerda. 65. Vista lateral direita com valva removida. Escala = $1 \mathrm{~mm}$.
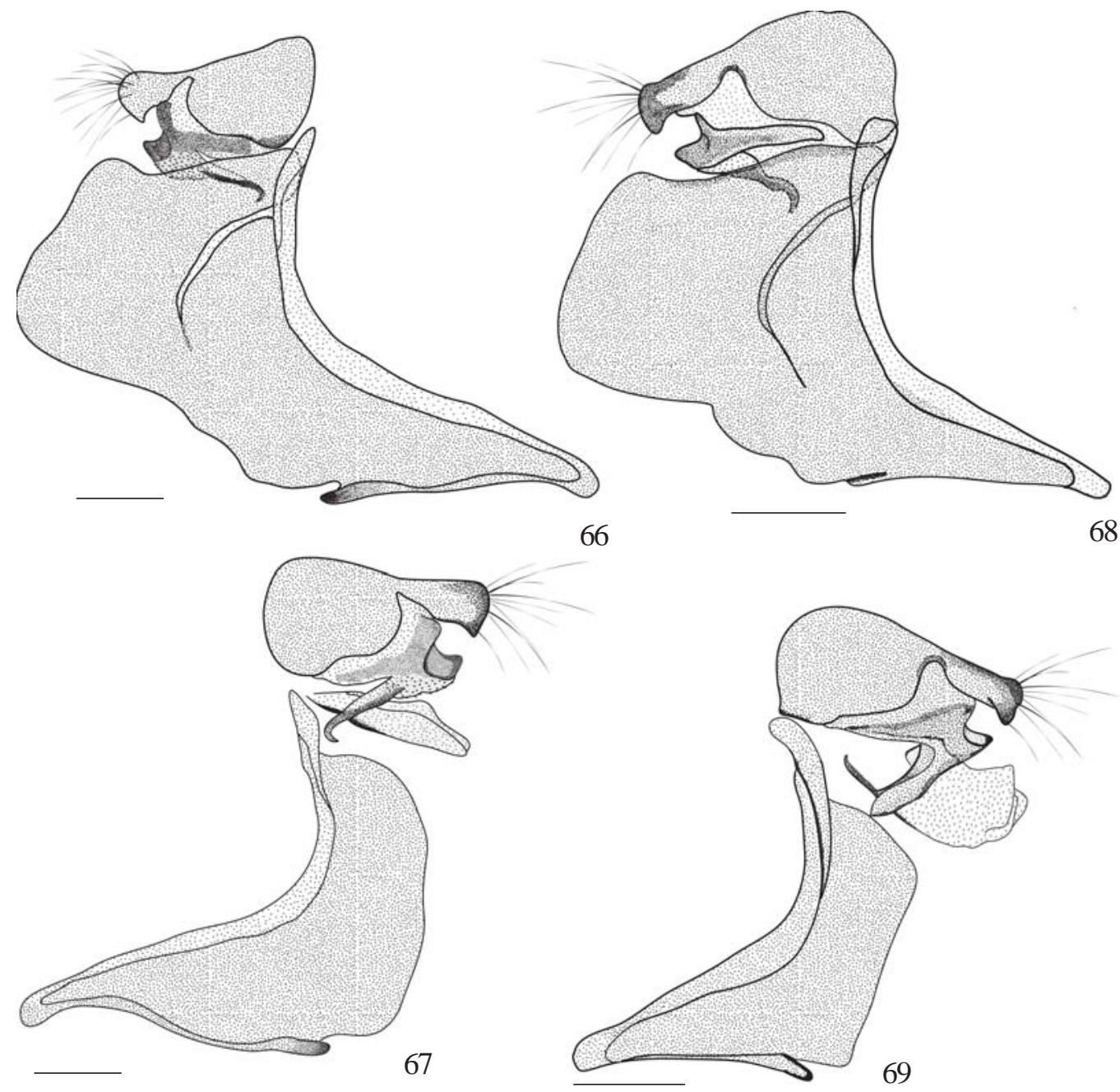

Figs. 66-69. Genitália masculina, vista lateral esquerda (com valva) e direita (sem valva). 66-67. T. syphax (Fabricius). 68-69. T. atymnius (Dalman) comb. nov. Escala $=1 \mathrm{~mm}$. 

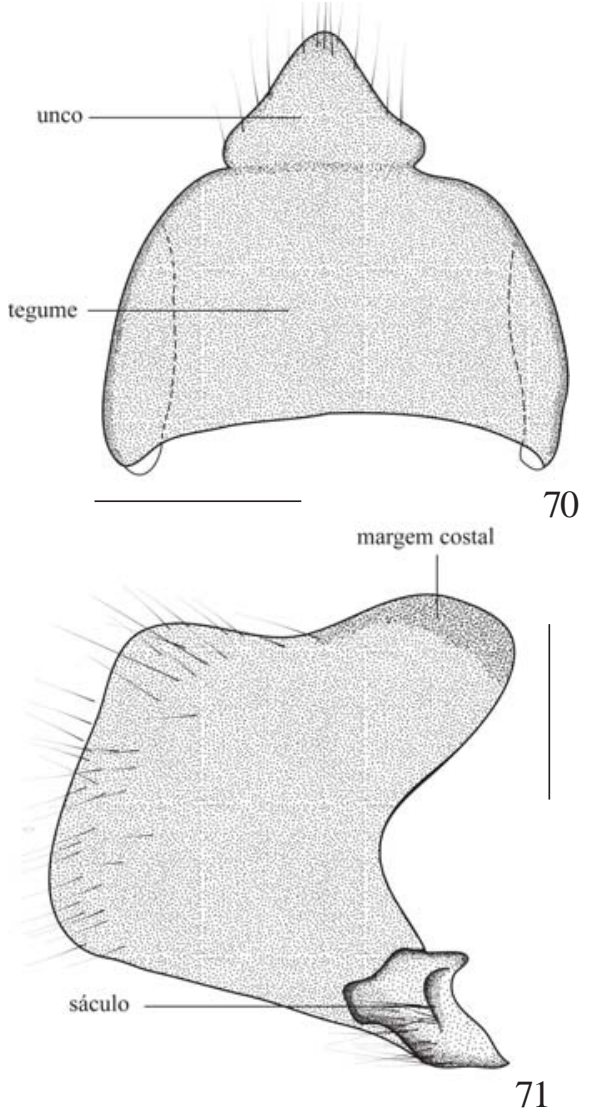

Figs. 70-71. Genitália masculina de T. licus (Drury). 70. Vista dorsal do tegume e unco. 71. Face interna da valva. Escala $=1 \mathrm{~mm}$.

1923), projetando-se anteriormente e fundindo-se com a região posterior do metatórax.

Esterno II mais desenvolvido que os demais, invaginandose anteriormente onde tem origem a barra pré-espiracular, auxiliando na articulação do tórax com o abdome (Figs. 58-63).

Demais segmentos abdominais sem modificações evidentes nas três espécies estudadas.

Genitália masculina (Figs. 64-84). Há pouco consenso entre os autores sobre quais segmentos formam a genitália masculina. São adotadas no presente trabalho as hipóteses de Snodgrass (1935), Michener (1944), Klots (1956) e Matsuda (1976), com base em estudos ontogenéticos que apontam o nono e o décimo segmentos abdominais como os principais envolvidos na formação da genitália.

Constituída pelas seguintes estruturas: tegume, vínculo, saco, valva, unco, gnato, e juxta, além do pênis com o bulbo ejaculatório, o edeago, a manica e a vesica.

Segundo a hipótese de homologia serial apresentada por Snodgrass (1935), a valva seria homóloga ao telepodito, formado pelo trocânter, fêmur, tíbia e tarso. A região proximal da valva estaria associada à placa coxo-esternal (nono segmento) que Snodgrass (1935: 602) chamou de vínculo, e a porção ântero-ventral dessa placa, ele chamou de saco. Essa interpretação é totalmente coerente com as descrições e ilustrações de Baker (1891: figs. 1, 2). O vínculo descrito por Pierce (1909), sinonimizado por ele mesmo (Pierce, 1914) como sendo o saco (sensu Baker 1891), não corresponde ao que Snodgrass (1935) chamou de vínculo. Por esse motivo, no presente estudo, empregamos os dois termos - vínculo e saco - em referência a duas estruturas distintas.

Nos Castniidae neotropicais, a placa coxo-esternal pode ser dividida em duas regiões: uma lateral, serialmente homóloga à coxa (Snodgrass 1935), com a qual a valva se articula; outra ventral, da qual partem as duas projeções anteriores do saco, afiladas nas três espécies aqui estudadas (Figs. 76, 78, 80).

Tegume derivado do nono tergo, arqueado em vista lateral (Figs. 64-69). Valva também derivada do nono segmento abdominal, com origem apendicular. Em Castniidae, assim como em outros grupos dentro de Lepidoptera, a valva pode ser subdividida em regiões, seguindo o trabalho de Sibatani et al. (1954); todavia deve-se ressaltar que não há consenso sobre a terminologia adotada para essas subdivisões, conforme se constata nos trabalhos de Forbes (1939), Sibatani et al. (1954) e Birket-Smith (1965), como também não há consenso sobre a homologia de suas estruturas. No entanto, algumas delas estão presentes em diferentes linhagens de Lepidoptera, possibilitando, dessa forma, recuperar a história evolutiva das estruturas e estabelecer as respectivas relações de homologia entre elas.
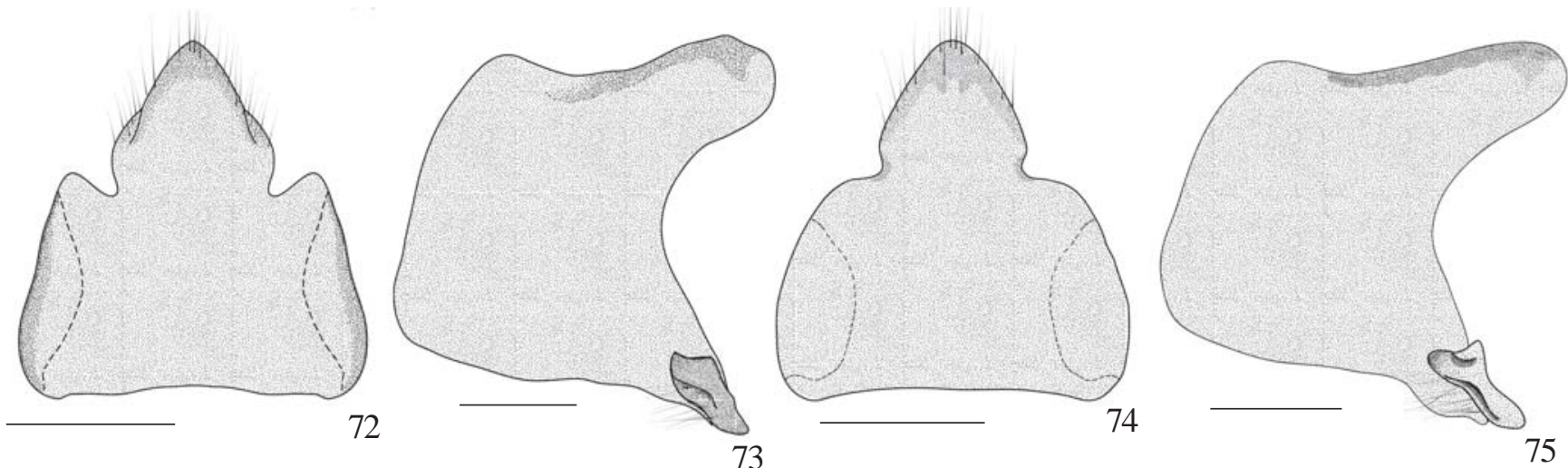

Figs. 72-75. Genitália masculina, vista dorsal do tegume e unco e face interna da valva. 72-73. T. syphax (Fabricius). 74-75. T. atymnius (Dalman) comb. nov. Escala $=1 \mathrm{~mm}$. 

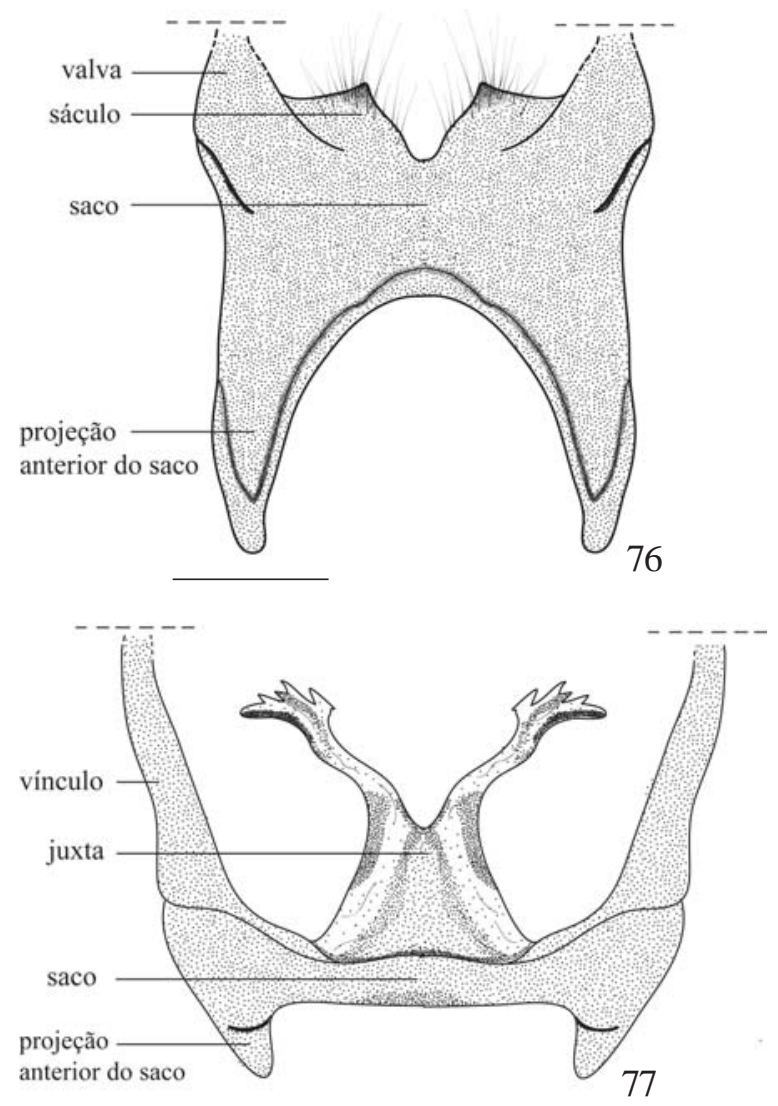

Figs. 76-77. Genitália masculina de T. licus (Drury). 76. Vista ventral do saco. 77. Vista frontal da juxta. Escala $=1 \mathrm{~mm}$.

Valva subquadrangular com margem ventral inclinada dorsalmente em relação ao eixo longitudinal do corpo (Figs. $71,74,75)$. Face interna com cerdas distribuídas principalmente na porção posterior; ântero-ventralmente com uma dobra pilosa denominada sáculo e nitidamente mais esclerotizada que o restante da valva (Figs. 71, 74, 75). Ainda na face interna e aderida a ela, na região proximal adjacente ao vínculo, nota-se uma membrana (anelífero sensu Pierce 1909; Sibatani et al. 1954) lateralmente estendida. Costa localizada na porção ântero-dorsal da valva e distintamente esclerotizada. Limite entre a valva e o vínculo não contínuo, tipicamente fundido pelo sáculo à região ventral do vínculo (Figs. 64, 66, 68) e ao saco (Figs. 76, 78, 80).

Décimo segmento abdominal representado pelo unco, derivado do tergo, e pelo gnato, derivado do esterno. Em vista dorsal, unco inteiro e triangular (Figs. 70, 72, 74); em vista lateral, com a extremidade posterior projetada ventralmente. Limite entre o tegume e o unco definido por tênue diferença de esclerotização e por inflexão nas margens laterais, visível principalmente em vistas dorsal e lateral; em vista dorsal, mais marcada em T. syphax (Fig. 72).

Gnato posicionado ventralmente ao unco e, em vista lateral, subdividido em duas partes: um braço dorsal distintamente esclerotizado; outro ventral, menos esclerotizado, denteado na região posterior e desviado mediamente na região anterior, envolvendo o tubo anal (Figs. 65, 67, 69).

Tubo anal localizado ventralmente ao tegume e unco, com a face ventral da extremidade posterior apresentando uma placa escletotizada conhecida como subescafo que, segundo Matsuda (1976), tem esclerotização secundária. Esclerotização do subescafo variando entre as espécies aqui estudadas, sendo mais esclerotizada em $T$. licus e T. syphax. Escafo aparentemente ausente.

Juxta como uma placa ventral, ligeiramente esclerotizada e anterior ao sáculo, servindo de suporte para o edeago; no material disponível para estudo (Tab. I), é caracterizada como uma extensão posterior do saco, menos conspícua em $C$. atymnius do que em T. licus e T. syphax (Figs. 77, 79, 81).

Bulbo ejaculatório expandido antes da inserção do duto ejaculatório, também conhecida como ceco, variando significativamente de comprimento entre os gêneros de Castniidae. O comprimento dessa estrutura parece ser filogeneticamente informativo quando comparado com a abertura do forame no bulbo, onde o ducto ejaculatório se insere. Em T. licus, T. syphax e C. atymnius, comprimento do ceco maior que a abertura do forame (Figs. 82-84).

Edeago recurvado e torcido, porção posterior alargada nas três espécies estudadas (Figs. 82-84), distinguindo-as dos demais Castniini (sensu Miller, 1995). Telchin licus com um
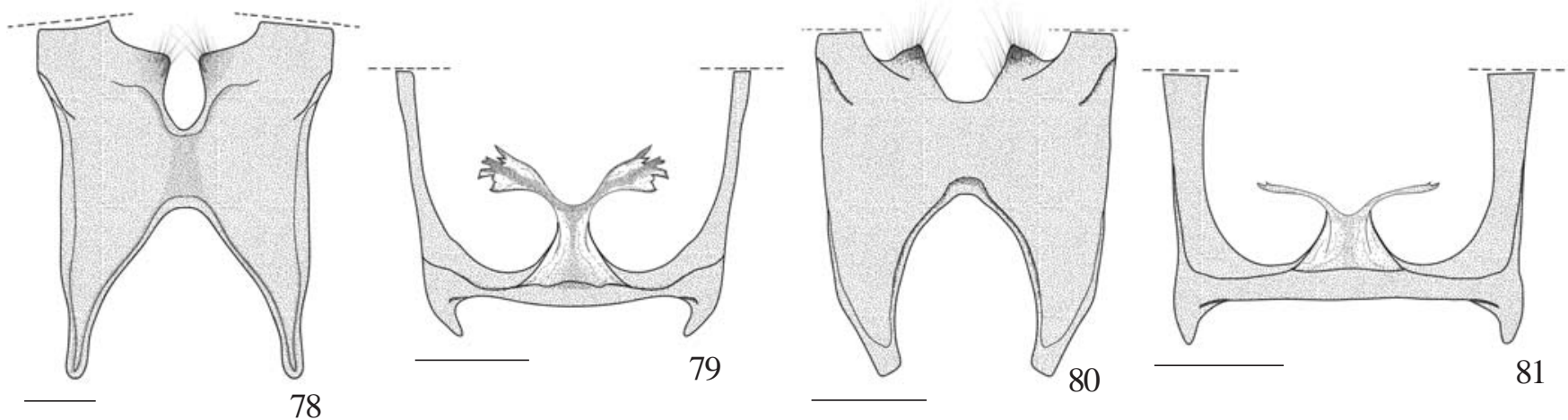

Figs. 78-81. Genitália masculina, vistas ventral do saco e frontal da juxta. 78-79. T. syphax (Fabricius). 80-81. T. atymnius (Dalman) comb. nov. Escala $=1 \mathrm{~mm}$. 


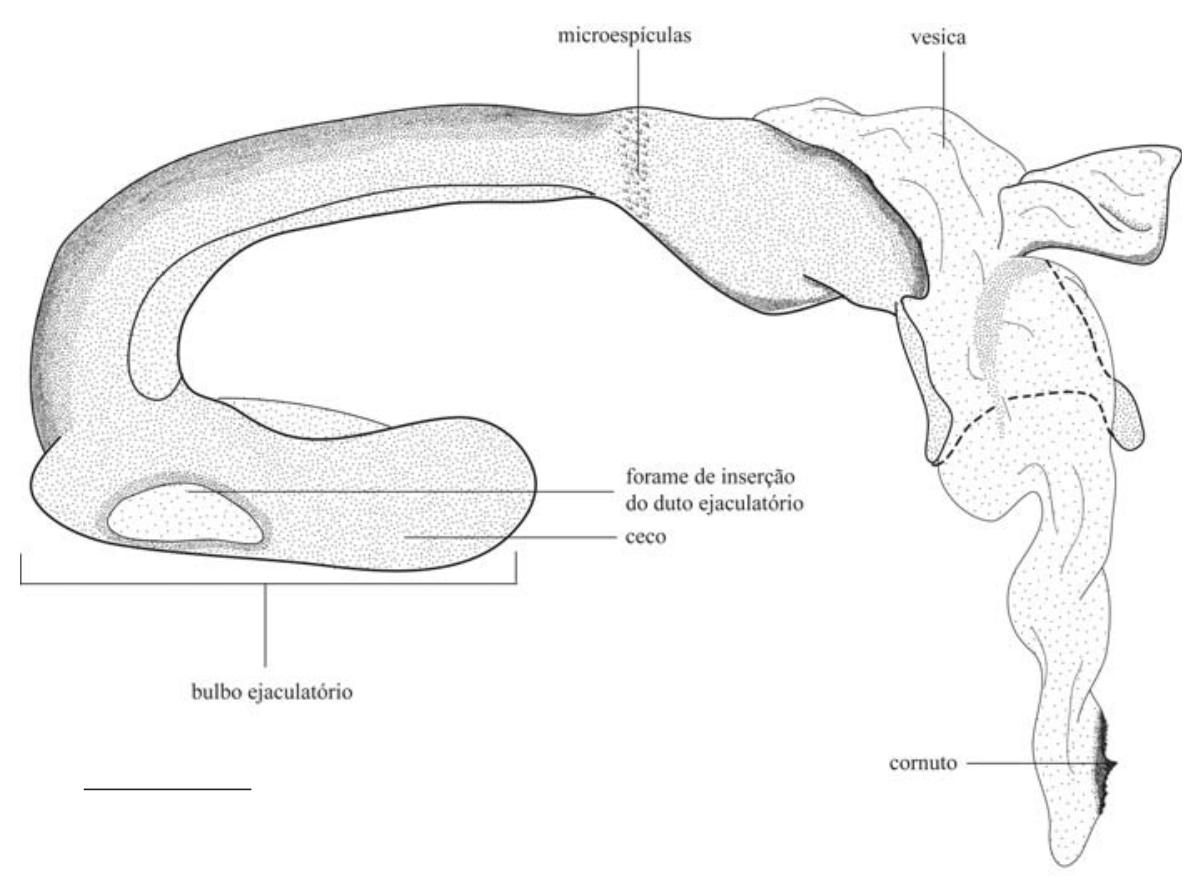

Fig. 82. Edeago de T. licus (Drury). Vista lateral. Escala $=1 \mathrm{~mm}$.

conjunto de microespículas na lateral direita da porção distal do edeago (Fig. 82); T. syphax e C. atymnius desprovidas dessas microespículas (Figs. 83, 84).

Manica, estrutura derivada da membrana intersegmental do nono, décimo e, possivelmente, do décimo primeiro segmento (Klots 1956), envolvendo o edeago desde sua região subterminal até a região da falobase, na inserção do duto ejaculatório no bulbo. Com tom amarelado, conferindo aparência de fraca esclerotização, diferentemente da maioria dos castníideos, onde a manica é totalmente translúcida e membranosa.

Vesica como uma membrana eversível na porção terminal e subterminal do edeago, com aparência bilobada; cornutos presentes, em forma de espinhos e implantados em uma placa esclerotizada, muito semelhante nas três espécies aqui estudadas (Figs. 82-84).

Genitália feminina (Figs. 85-93). Em Lepidoptera, o ovipositor não possui origem gonapofiseal, ao invés disso ele é formado pelo prolongamento dos últimos segmentos abdominais (Matsuda 1976). Formada a partir do oitavo, nono e décimo segmentos abdominais, a genitália feminina possui estrutura simplificada quando comparada com a masculina.

Antro tão largo quanto longo, com estrias esclerotizadas em toda sua extensão (Figs. 86, 89, 92). Extremidade anterior conectada a dois dutos: duto da bolsa com uma porção lisa e outra espiralada; duto seminal, levemente estriado. Nas espécies estudadas no presente trabalho não houve variação nos elementos da bolsa.

Duto da bolsa originando-se na porção dorsal do antro, com a porção inicial lisa e a porção terminal, a qual se liga à bolsa, espiralada e ornamentada com diminutas espículas. $\mathrm{O}$ número de voltas que a porção espiralada apresenta é constante nas três espécies (cinco voltas), entretanto esse número pode variar em outros gêneros de Castniidae (S.S. Moraes, em preparação).

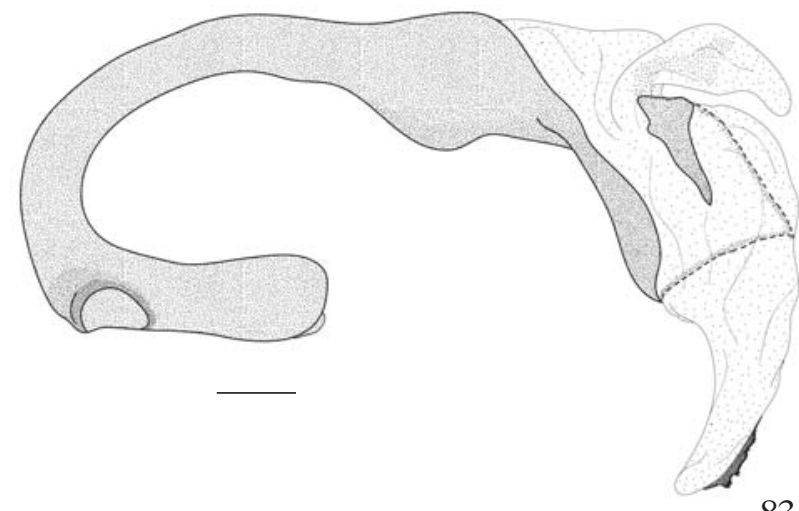

83

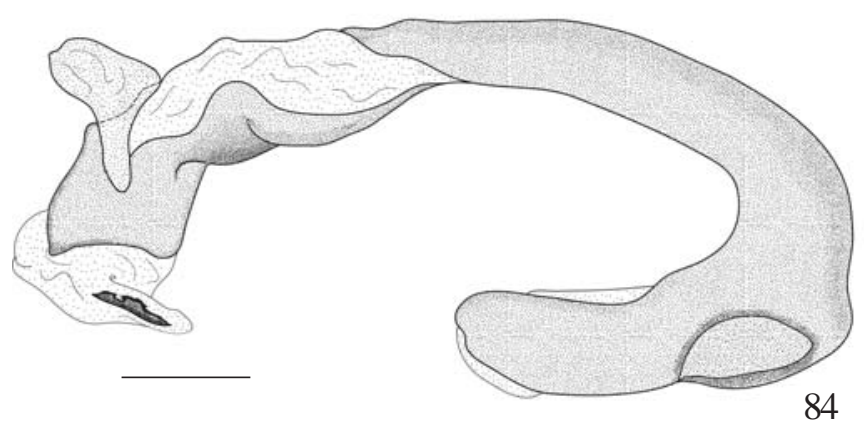

Figs. 83-84. Edeago, vista lateral. 83. T. syphax (Fabricius). 84. T. atymnius (Dalman) comb. nov. Escala $=1 \mathrm{~mm}$. 

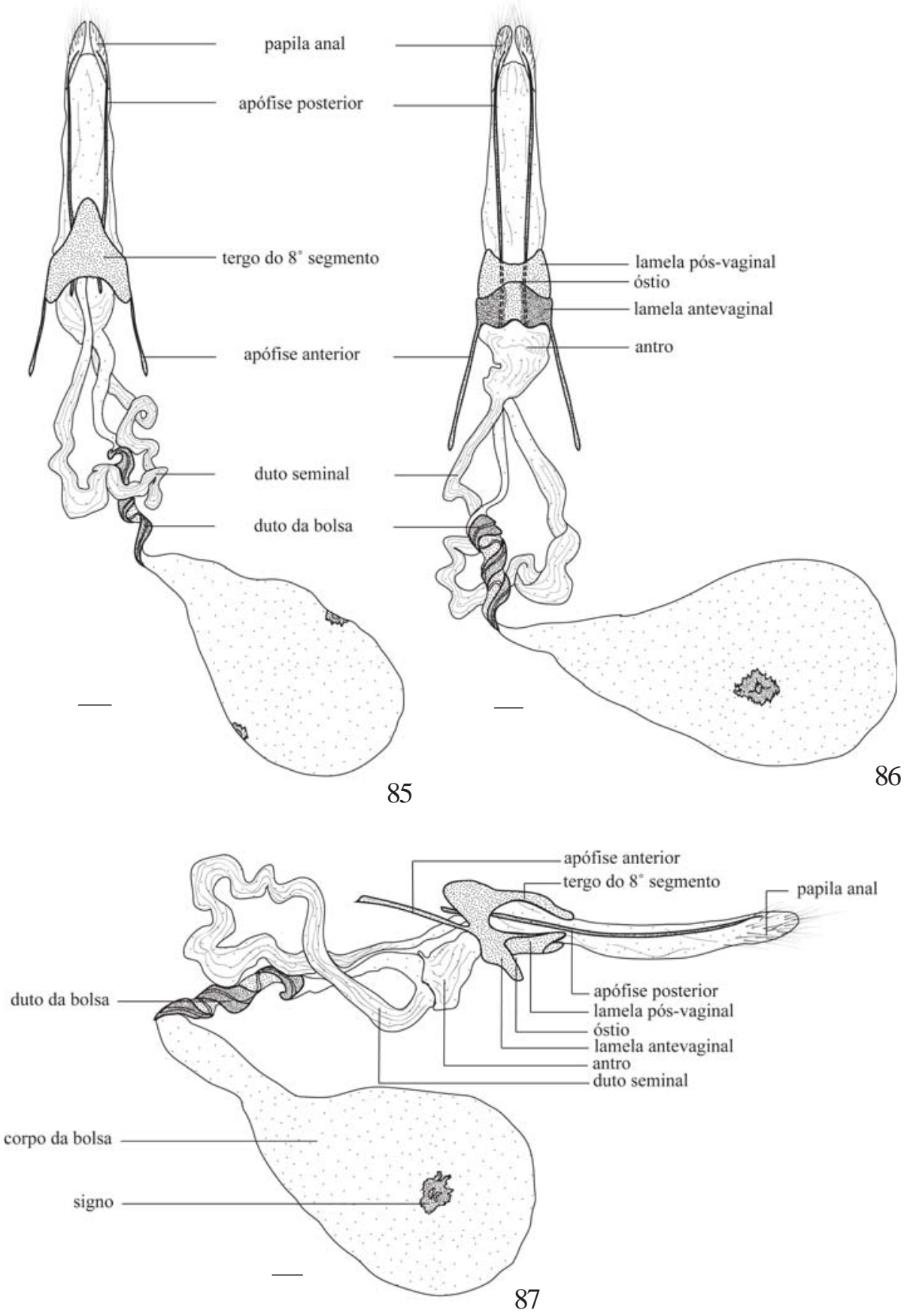

Figs. 85-87. Genitália feminina de T. licus (Drury). 85. Vista dorsal. 86. Vista ventral. 87. Vista lateral. Escala $=1 \mathrm{~mm}$.

Corpo da bolsa com signos constituídos de duas placas esclerotizadas, subcirculares, dispostas simetricamente nas laterais; placas com dentes de tamanho reduzido na periferia e dentes mais proeminentes na região central.

Duto seminal com origem na região ventral do antro e terminando no oviporo (Figs. 87, 90, 93). Bula seminal variável nos gêneros de Castniidae, porém distinta ao longo do duto seminal, podendo ser bulbosa e conter raios esclerotizados, como por exemplo, em Synpalamides Hübner, [1823] e Hista Oiticica, 1955, ou alongada, com aparência túrgida e ornamentada com microespículas ao longo da superfície externa, como em Eupalamides Hübner, [1823], Imara Houlbert, 1918 e Geyeria Buchecker, [1880]. Em T. licus, T. syphax e C. atymnius, mantendo proporções indistintas do restante do duto seminal e ornamentada com microespículas.

Margens anteriores do oitavo e nono segmentos abdominais com dois longos pares de apófises (anteriores e posteriores), auxiliando na inserção de músculos destinados à retração e à distensão da genitália. Comprimento das apófises subigual nas três espécies (Figs. 87, 90, 92). 


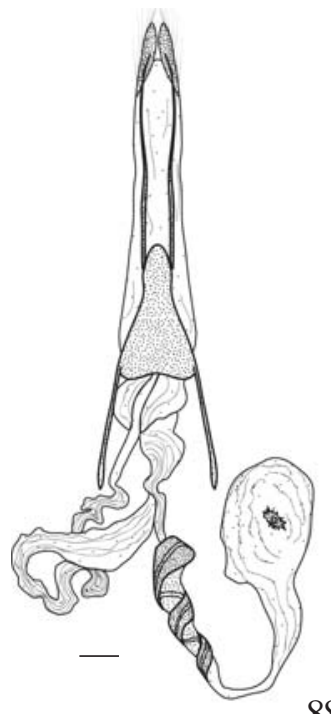

88

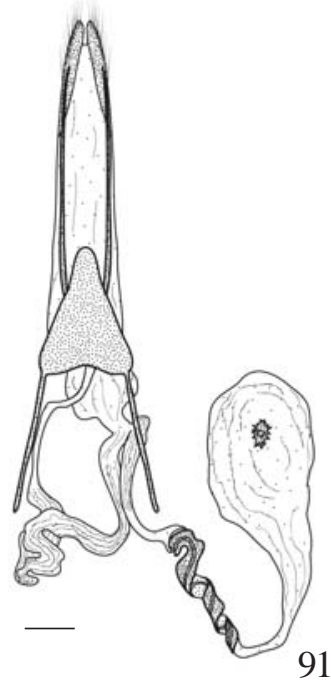

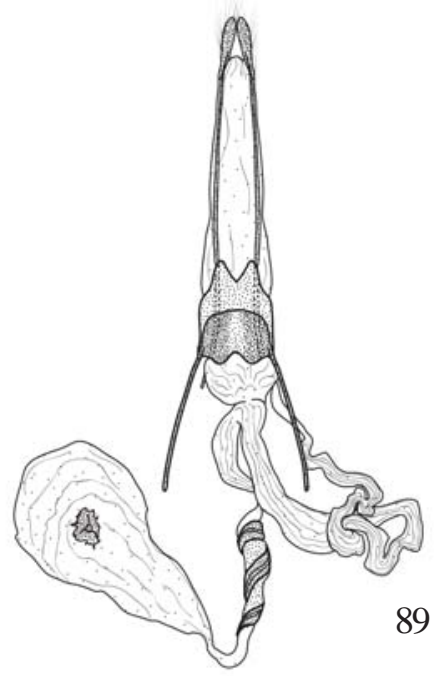

89

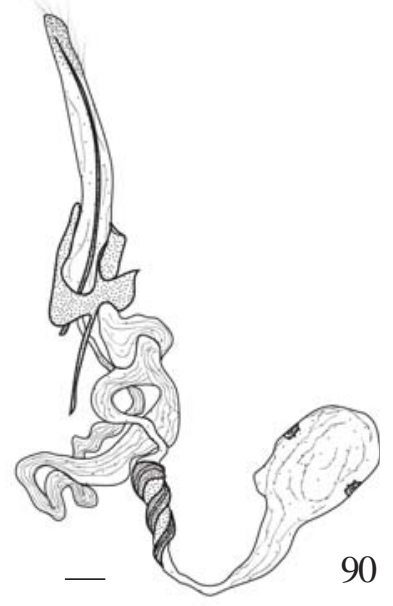

90
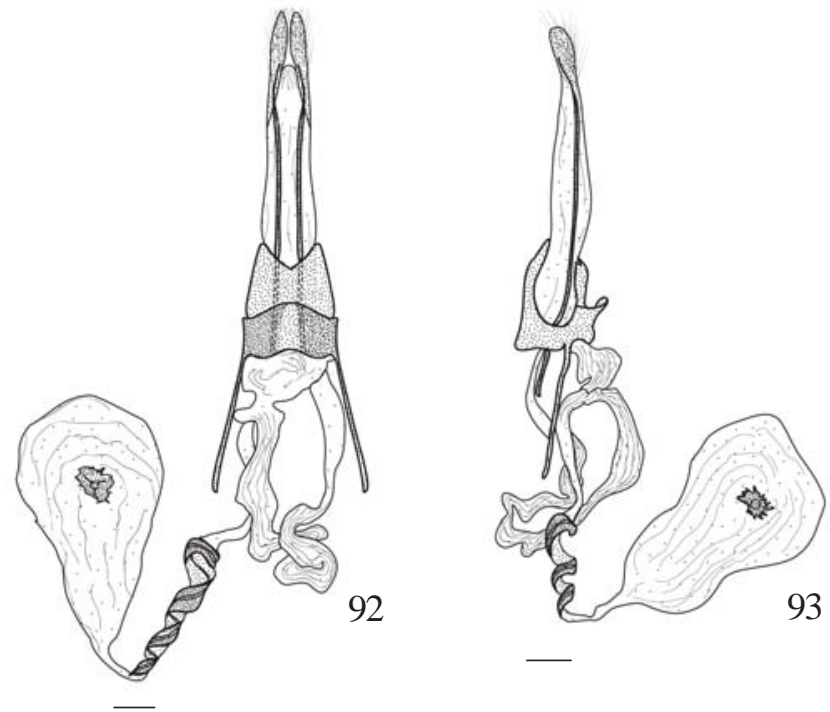

Figs. 88-93. Genitália feminina, vistas dorsal, ventral e lateral (esquerda para direita). 88-90. T. syphax (Fabricius). 91-93. T. atymnius (Dalman) comb. nov. Escala $=1 \mathrm{~mm}$.

Tergo do oitavo segmento em forma de triângulo isósceles; em T. syphax, comprimento do tergo ligeiramente maior do que em T. licus e C. atymnius (Figs. 85, 88, 91).

Região ventral do oitavo segmento abdominal representada pelas lamelas antevaginal e pós-vaginal, com uma pequena abertura entre elas, o óstio da bolsa. Lamela antevaginal aparentemente formada pelas extensões laterais das apófises anteriores, às vezes ausente, como em Castnia invaria Walker, 1854. As extensões podem ser variáveis e geralmente apresentam uma região mediana membranosa ou de esclerotização variável, como observado em Feschaeria amycus (Cramer, [1779]) e Geyeria decussata (Godart, [1824]), respectivamente. Telchin licus, T. syphax e C. atymnius com lamela antevaginal em forma de placa única, menos esclerotizada (Figs. 86, 89, 92). Em vista ventral, margem posterior da lamela pós-vaginal com reentrância, menos acentuada em T. licus (Figs. 86, 89, 92).
Nono e décimo segmentos fundidos, representados por um par de estruturas pareadas lateralmente, as papilas anais, sem variações nas espécies estudadas (Figs. 85-93).

\section{CONCLUSÕES}

A morfologia dos adultos de T. licus, T. syphax e $C$. atymnius é notavelmente uniforme mesmo para as genitálias masculina e feminina que, em geral, servem como fontes de caracteres na identificação e classificação das espécies de Lepidoptera (Scudder, 1971). No entanto, algumas diferenças encontradas no presente trabalho, como o grau de esclerotização dos escleritos e suturas e a pigmentação de determinadas áreas da cabeça, do tórax e das genitálias, podem representar características individuais ou artefatos do tempo de exposição ao hidróxido de potássio. Outras pequenas diferenças morfológicas encontradas são ainda menos 
relevantes quando comparadas com as de outros gêneros de Castniini (Miller 1986). Não obstante a essas pequenas diferenças, o que fica evidente é a grande semelhança morfológica entre as três espécies, principalmente no que diz respeito à genitália masculina. Outros gêneros de Castniini têm tido seus limites bem definidos com base em caracteres de genitália (Miller 1986), o que não ocorre com os gêneros Telchin e Castniomera.

Devido à escassez de caracteres morfológicos informativos, os caracteres usualmente adotados para classificar ou mesmo rearranjar categoricamente as espécies do complexo T. licus, são provenientes do padrão de coloração das asas (Miller 1986; González \& Cock 2004). Miller (1986) eliminou de sua análise caracteres referentes à coloração alar argumentando que, com a diversidade apresentada pela subfamília Castniinae, em especial os representantes neotropicais, não teria como determinar a polaridade dos caracteres.

Tendo em vista que parte dos representantes neotropicais de Castniinae está envolvida em complexos miméticos (Lamas 1973; Miller 1986), o padrão de coloração alar é muito variável e sujeito à influência do meio. Além disso, a ampla distribuição dessas espécies e a dificuldade de se estabelecer limites biogeográficos bem definidos, particularmente para T. licus e C. atymnius, com muitas subespécies ao longo da região neotropical, faz com que caracteres de coloração não sejam os mais adequados no resgate das relações filogenéticas do grupo. Ainda é necessário um estudo detalhado dos padrões de coloração alar em Castniidae a fim de se estabelecer as possíveis homologias entre eles (ver Miller 1996; Nijhout 1991).

Apesar de possuírem diferenças no padrão de máculas das asas posteriores, as semelhanças morfológicas da cabeça, do tórax e das genitálias masculina e feminina, aliadas ao fato de outros gêneros pertencentes à Castniini possuírem diferenças mais discrepantes dos que as apresentadas pelos gêneros Telchin e Castniomera, mostram-se como evidências fortes para justificar a inclusão de C. atymnius em Telchin. Assim Castniomera Houlbert, 1918 torna-se sinônimo de Telchin Hübner 1825, que passa a ser constituído por T. licus, T. syphax e T. atymnius, combinação nova.

Embora o agrupamento de espécies dentro de categorias taxonômicas ainda seja subjetivo para alguns grupos de animais e vegetais (Bernardi 1994), os dados morfológicos apresentados no presente estudo suportam o novo arranjo taxonômico do complexo T. licus.

Ainda que o presente estudo não tenha revelado diferenças morfológicas significativas que pudessem contribuir para um melhor entendimento das relações de parentesco entre as três espécies do complexo T. licus, ele contribui para o entendimento morfológico e proporciona uma alternativa à taxonomia do complexo. Quando uma análise morfológica resulta na ausência de caracteres informativos para produção de uma filogenia robusta, ou ainda, quando é necessária uma filogenia independente para investigação da evolução de caracteres morfológicos, a análise de dados moleculares apresenta-se como uma alternativa para ampliar o conhecimento sobre um determinado grupo de organismos (Brown et al. 1999).
Agradecimentos. O presente trabalho é parte do projeto "Sistemática, Bionomia e Evolução de Lepidoptera Neotropicais (Insecta)" apoiado pela Fundação de Amparo à Pesquisa do Estado de São Paulo (FAPESP processo número 2002/13898-0). O autor sênior é grato à FAPESP pela bolsa de mestrado (processo número 2006/053653). Auxílios complementares foram concedidos pela Pró-Reitoria de Pesquisa da Universidade de São Paulo (processos 2004.1.8047.1.0/ 2006.1.147.38.6/ 2007.1.61.38.5/2008.1.110.38.7). Os autores são ainda gratos ao Dr. Jorge M. González (Texas A\&M University) pela constante colaboração nos estudos com Castniidae, à Dra. Patricia Gentili pelo apoio técnico durante nossa visita ao National Museum of Natural History, ao Dr. Vitor O. Becker e família pela especial acolhida do autor júnior na Reserva Serra Bonita (Camacã, BA), ao doutorando Guilherme Ide Marques dos Santos (MZUSP) pelo auxílio no tratamento das fotos coloridas, ao mestrando Pedro Augusto da Pós Rodrigues (UNICAMP) e a dois revisores anônimos pela leitura crítica do manuscrito.

\section{REFERÊNCIAS}

Baker, G. T. 1891. Notes on the genitalia of a gynandromorphus Eronia hippia. Transactions of the Entomological Society of London 1: $1-6$.

Bernardi, N. 1994. Nomenclatura zoológica, p. 169-186. In: N. Papavero (ed.). Fundamentos Práticos de Taxonomia Zoológica. São Paulo, Editora UNESP, 285 p.

Birket-Smith, J. 1965. A revision of West African Eilemic moths, based on male genitalia (Lep. Arctidae [sic], Lithosinae [sic]; incl. genera Crocosia, Eilema, Lithosla, Pelosia, Phyganopka). Papers from the Faculty of Science Haile Sellassie I University Series C (Zoology) 1: 1-162.

Birket-Smith, J. 1974. Morphology of the male genitalia of Lepidoptera I. Ditrysia. Entomologica Scandinavica 5: 1-22.

Brown, B.; R. M. Emberson \& A. M. Paterson. 1999. Phylogeny of "Oxyсапиs" lineages of hepialid moths from New Zealand inferred from sequence variation in the mtDNA COI and II gene regions. Molecular Phylogenetics and Evolution 13: 463-473.

Camargo, A. J. A.; M. M. Casagrande; O. H. H. Mielke \& E. Furtado. 2005. Morfologia externa do adulto de Almeidaia aidae Mielke \& Casagrande (Lepidoptera, Saturniidae, Arsenurinae, Almeidaiini) I. Cabeça, apêndices e região cervical. Revista Brasileira de Zoologia 22: 619-622.

de Pinna, M. C. C. 1991. Concepts and tests of homology in the cladistic paradigm. Cladistics 7: 367-394.

Duarte, M. 2007. Morfologia externa do adulto de Hemiargus hanno (Lepidoptera, Lycaenidae, Polyommatinae, Polyommatini). II. Região cervical, tórax e abdome. Iheringia, Série Zoologia, 97: 194-206.

Duarte, M.; M. M. Casagrande \& O. H. H. Mielke. 2001. Morfologia externa do adulto de Hemiargus hanno (Stoll) (Lepidoptera, Lycaenidae, Polyommatinae, Polyommatini). I. Cabeça. Revista Brasileira de Zoologia 18: 225-238.

Edwards, E. D.; P. Gentili; M. Horak; N. P. Kristensen \& E. S. Nielsen. 1998. The Cossoid/ Sesioid assemblage, p 181-197. In: M. Fischer (ed.). Band/ Volume IV Arthropoda: Insecta. Lepidoptera, Moths and Butterflies: Evolution, Systematics, and Biogeography. In: M. Fischer (ed.). Handbuch der Zoologie. Handbook of Zoology. Berlin, Walter de Gruyter. v. 1, 491 p.

Ehrlich, P. R. 1958. The integumental anatomy of the Monarch butterfly Danaus plexippus L. (Lepidoptera: Danaidae). The University of Kansas Science Bulletin 38: 1315-1349.

Ehrlich, P. R. 1960. The integumental anatomy of the silver-spotted skipper, Epargyreus clarus Cramer (Lepidoptera: Hesperiidae). Microentomology 24: 1-23.

Ehrlich, P. R. \& A. H. Ehrlich. 1961. How to know the butterflies. Dubuque, Brown Company Publishers, 266 p.

Espinoza, B. \& J. M. González. 2005. Description of a new species of Imara Houlbert, 1918 (Lepidoptera, Castniidae). Zootaxa 849: 1-8. 
Forbes, W. T. M. 1923. The Lepidoptera of New York and neighboring states. Ithaca, New York, Cornel University Press, $729 \mathrm{p}$.

Forbes, W. T. M. 1939. The muscles of the lepidopterous male genitalia. Annals of the Entomological Society of America 32: 1-10.

González, J. M. 2003. Castniinae (Lepidoptera: Castniidae) from Venezuela. V: Castnia Fabricius and Telchin Hübner. Boletín del Centro de Investigaciones Biológicas 37: 191-201

González, J. M., \& M. J. W. Cock. 2004. A synopsis of the Castniidae (Lepidoptera) of Trinidad and Tobago. Zootaxa 762: 1-19.

Houlbert, C. 1918. Révision monographique de la sous-famille des Castniinae. Etudes de Lépidoptérologie Comparée 15: 1-730.

Jordan, H. E. K. 1923. On the scent-organs in the males of certain American Castniidae. Novitates Zoologicae 30: 155-158.

Klots, A. B. 1956. Lepidoptera, p. 97-110. In: L. S. Tuxen (ed.). Taxonomist's Glossary of Genitalia in Insects. Copenhagen, Munksgaard, $359 \mathrm{p}$.

Lamas, G. 1973. Taxonomia e evolução dos gêneros Ituna Doubleday (Danainae) e Paititia, gen. nov., Thyridia Hübner e Metona Doubleday (Ithomiinae). Tese de Doutorado. São Paulo, Universidade de São Paulo, 255 p.

Lamas, G. 1995. A critical review of Miller's checklist of the Neotropical Castniidae (Lepidoptera). Revista Peruana de Entomologia 37: $73-87$.

Madden, A. H. 1944. The external morphology of the adult tobacco hornworm (Lepidoptera, Sphingidae). Annals of the Entomological Society of America 37: 145-160.

Matsuda, R. 1965. Morphology and evolution of the insect head. Memories of the American Entomological Institute 4: 1334.

Matsuda, R. 1970. Morphology and evolution of the insect thorax. Memoirs of the Entomological Society of Canada 76: 1-431.

Matsuda, R. 1976. Morphology and evolution of the insect abdomen: with special reference to developmental patterns and their bearings upon systematics. New York, Pergamon Press, 533 p.

Michener, C. D. 1952. The Saturniidae (Lepidoptera) of the western hemisphere: morphology, phylogeny, and classification. Bulletin of the American Museum of Natural History 98: 335-502.

Mielke, C. G. C.; O. H. H. Mielke \& M. M. Casagrande. 2004a. Estudo comparado da morfologia externa de Zaretis itys itylus (Westwood) e Agrias claudina annetta (Gray) (Lepidoptera, Nymphalidae, Charaxinae). I. Cabeça, apêndices e região cervical. Revista Brasileira de Zoologia 21: 357-369.

Mielke, C. G. C.; O. H. H. Mielke \& M. M. Casagrande. 2004b. Estudo comparado da morfologia externa de Zaretis itys itylus (Westwood) e Agrias claudina annetta (Gray) (Lepidoptera, Nymphalidae, Charaxinae). II. Tórax e apêndices. Revista Brasileira de Zoologia 21: 421-433.

Mielke, C. G. C.; O. H. H. Mielke \& M. M. Casagrande. 2004c. Estudo comparado da morfologia externa de Zaretis itys itylus (Westwood) e Agrias claudina annetta (Gray) (Lepidoptera, Nymphalidae, Charaxinae). III. Abdome. Revista Brasileira de Zoologia 21: 905-912.

Miller, J. S. 1996. Phylogeny of the Neotropical moth tribe Josiini (Notodontidae: Dioptinae): a hidden case of Müllerian mimicry. Zoological Journal of the Linnean Society 118: 1-45.

Miller, J. Y. 1971. The head capsule of selected Hesperioidea. Journal of Research on the Lepidoptera 9: 193-214.

Miller, J. Y. 1986. The taxonomy, phylogeny and zoogeography of the Neotropical moth subfamily Castniinae (Lepidoptera, Castnioidea: Castniidae). PhD Dissertation. Gainesville, University of Florida, 571 p.
Miller, J. Y. 1995. Castniidae, p. 133-137, 176-177. In: J. B. Heppner (ed.). Checklist: Part 2. Hyblaeoidea-PyraloideaTortricoidea. In: Atlas of Neotropical Lepidoptera. Gainesville, Association for Neotropical Lepidoptera/ Scientific Publishers, 243 p.

Miller, J. Y. 2000. Castniidae (Lepidoptera), p. 527-533. In: J. E. Llorente, E. González \& N. Papavero (eds.). Biodiversidad, taxonomía y biogeografía de artrópodos de México: Hacia uma síntesis de su conocimento. Volume 2. México, Universidad Nacional Autónoma de México, 676 p.

Mutuura, A. 1972. Morphology of the female terminalia in Lepidoptera, and its taxonomic significance. Canadian Entomologist 104: 1055-1071.

Nijhout, H. F.1991. The development and evolution of butterfly wing patterns. Washington, D.C., Smithsonian Institution Press, 297 p.

Ogata, M.; Y. Okada; H. Okagaki \& A. Sibatani. 1957. Male genitalia of Lepidoptera: morphology and nomenclature III. Appendages pertaining to the tenth somite. Annals of Entomological Society of America 50: 237-244.

Okagaki, H.; A. Sibatani; M. Ogata \& Y. Okada. 1955. Male genitalia of Lepidoptera: morphology and nomenclature II. Morphological significance of sacculus and furca. Annals of Entomological Society of America 8: 438-442.

Pierce, F. N. 1909. The genitalia of the group Noctuidae of the Lepidoptera of the British Islands. An account of the morphology of the male clasping organs. Liverpool, A. W. Duncan, $88 \mathrm{p}$.

Pierce, F. N. 1914. The genitalia of the group Geometridae of the Lepidoptera of the British Islands. An account of the morphology of the male clasping organs and the corresponding organs of the female. Liverpool, A. W. Duncan, $84 \mathrm{p}$.

Pierre, J. \& C. Pierre-Baltus. 2003. Un nouveau Castnia endémique de la Martinique (Lepidoptera, Castniidae). Bulletin de la Societé Entomologique de France 108: 437-439.

Porion, T. 2004. Castnius asteropoides n. sp. nouveau castniide neotropical (Lepidoptera, Castniidae). Lépidoptères 2: 47-50.

Scoble, M. J. 1992. Lepidoptera form, function and diversity. New York, Oxford University Press, $440 \mathrm{p}$.

Scudder, G. G. E. 1971. Comparative morphology of insect genitalia. Annual Review of Entomology 16: 379-406.

Sharplin, J. 1963. Wing base structure in Lepidoptera. I: Forewing base. Canadian Entomologist 95: 1121-1145.

Shepard, H. H. 1930. The pleural and sternal sclerites of the lepidopterous thorax. Annals of the Entomological Society of America 23: 237-260.

Sibatani, A.; M. Ogata; Y. Okada \& H. Okagaki. 1954. Male genitalia of Lepidoptera: Morphology and Nomenclature. I. Divisions of the valvae in Rhopalocera, Phalaenidae (= Noctuidae) and Geometridae. Annals of Entomological Society of America 47: 93-106.

Snodgrass, R. E. 1935. Principles of insect morphology. New York, McGraw-Hill Book Company, 667 p.

Sorensen, J. T. 1980. An integumental anatomy for the butterfly Glaucopsyche lygdamus (Lepidoptera: Lycaenidae): a morphological terminology and homology. Zoological Journal of the Linnean Society 50: 55-101.

Strand, E. 1913. Castnia, p. 7-17, pls. 1-8. In: A. Seitz (ed.). The macrolepidoptera of the American region. 6. Bombyces and Sphinges. Stuttgart, Alfred Kernen Verlag.(Footnotes) 